\title{
Improved Representation of Upper-Ocean Dynamics and Mixed Layer Depths in a Model of the North Atlantic on Switching from Eddy-Permitting to Eddy-Resolving Grid Resolution
}

\author{
ANDREAS Oschlies \\ Institut für Meereskunde an der Universität Kiel, Kiel, Germany
}

(Manuscript received 15 June 2001, in final form 28 November 2001)

\begin{abstract}
Two configurations of a primitive-equation model of the North Atlantic are analyzed with respect to the simulated cycling of energy, mass, and heat in the upper ocean. One model is eddy-permitting $\left(1^{\circ}{ }^{\circ}\right.$ horizontal resolution), the other one is eddy-resolving $\left(19^{\circ}\right.$ resolution), with both models using identical topographies and identical forcing fields at the surface and lateral boundaries. Besides showing some improvement in the simulated mean circulation and heat budgets, the eddy-resolving model reaches good agreement with satellite altimeter measurements of sea surface height variability. An unexpected finding of the model intercomparison is that simulated winter mixed layer depths in mid and high latitudes turn out to be systematically shallower by some 50 to $500 \mathrm{~m}$ in the higher resolution run, thereby agreeing better with observations than the $1 /{ }^{\circ}$ model results. This model improvement is related to enhanced levels of baroclinic instability leading to a decrease in potential energy and an associated increase in stratification. In the high-resolution model, shear-induced tilting of lateral density gradients generates stratification within the mixed layer itself, at a rate sufficient to set off an average surface heat loss of $5 \mathrm{~W} \mathrm{~m}^{-2}$ in mid and high latitudes. Although this is small compared to present uncertainties in surface heat fluxes, the resulting reduction in mixed layer depths may be important for an accurate simulation of water mass formation, air-sea gas exchange, and marine biological production. With traditional formulations of mixed layer physics assuming that properties are set by purely vertical mixing, and parameterizations of lateral subgrid-scale mixing often being tapered to zero in the mixed layer, present mixing schemes would have to be modified in order to account for eddy-induced generation of stratification in the surface mixed layer in noneddy-resolving ocean models.
\end{abstract}

\section{Introduction}

Almost everywhere in the open ocean is the kinetic energy of the flow field dominated by mesoscale variability, with spatial scales varying roughly from some 10 $\mathrm{km}$ in subpolar regions to a few $100 \mathrm{~km}$ in the Tropics. The potential impact of these energetic fluctuations on temporal and spatial mean properties of the ocean and associated large-scale transport of heat, energy, mass, and biogeochemical tracers has been the subject of a number of investigations in past decades. Many of these studies relied on numerical ocean circulation models of $13^{\circ}$ to $1 \%^{\circ}$ horizontal resolution in idealized (e.g., Barnier et al. 1991; Böning and Budich 1992; Drijfhout 1994; McGillicuddy and Robinson 1997) or realistic basin configurations (Beckmann et al. 1994; Chao et al. 1996; Oschlies and Garçon 1998; Willebrand et al. 2001). Only recently has it become feasible to run basin-scale primitive-equation models with even finer resolution necessary to resolve

Corresponding author address: Dr. Andreas Oschlies, Institut für Meereskunde an der Universität Kiel, Dusternbrooker Weg 20, Kiel 24105, Germany.

E-mail: aoschlies@ifm.uni-kiel.de mesoscale features at mid and high latitudes (e.g., Paiva et al. 1999). A major breakthrough in this respect was documented by Smith et al. (2000), who could demonstrate significant improvement of the simulated eddy kinetic energy as well as of mean properties like the representation of the Gulf Stream when horizontal resolution was refined from $14_{4}^{\circ}$ to $1 / 10$.

Although earlier studies used the term "eddy resolving" for the then highest possible resolution of about $\frac{1}{3}{ }^{\circ}$, it turned out that such a resolution was not sufficient to adequately describe the eddy field in mid and high latitudes (Treguier 1992). In addition to a general underestimation of eddy activity, simulated eddy scales were systematically overestimated in regions where the first baroclinic Rossby radius was not resolved (Stammer and Böning 1992). In the context of primitive-equation models, the term eddy resolving has now become more popular for models that approximately resolve the first baroclinic Rossby radius, whereas models with a grid spacing finer than typical eddy scales but coarser than the Rossby radius are commonly termed "eddy permitting." In the present study such an eddy-resolving model is compared with an eddy-permitting one, with both model configurations being identical except for the horizontal grid spacing. 
The main emphasis here is to examine the effect of increased horizontal resolution on the distribution and fluxes of energy, mass, and heat in the upper ocean (down to about $1000 \mathrm{~m}$ ) and resulting effects on mean stratification and the depth of the surface mixed layer. The focus on the upper ocean was motivated by the ongoing analysis of a pelagic ecosystem model (Oschlies and Garçon 1999) coupled into both models but not considered further in this study. An unexpected result of the coupled ecosystem-circulation model were systematically shallower winter mixed layers in mid and high latitudes simulated by the eddy-resolving model. This has an immediate effect on seasonal nutrient supply, which was too high in previous studies relying on the eddy-permitting model version that generated unrealistically deep winter mixing in the northern North Atlantic (Oschlies et al. 2000). The present study investigates the mechanisms responsible for the reduction in mixing depth on refining the horizontal grid resolution. Idealized model studies have demonstrated that three-dimensional processes like baroclinic instability and associated tilting of lateral density gradients within the mixed layer can lead to a systematic reduction of mixing depths compared to a purely one-dimensional treatment of vertical mixing (Haine and Marshall 1998; Legg et al. 1998; Nurser and Zhang 2000). Here, the effect of resolving three-dimensional generation of stratification in the mixed layer will be examined for a realistic basin-scale model. In order to establish some confidence into the general model performance, the paper also briefly presents mean state and statistical properties of the simulated flow field.

The paper is organized as follows: Section 2 gives a brief description of the model configurations. To put this model study into reference to the pioneering work of Smith et al. (2000), a brief overview of changes in the simulated mean transports of volume and heat that arise from a refinement of the horizontal grid resolution from $1 / 3$ to $1 /{ }^{\circ}$ follows in section 3 . The impact of changing the grid resolution on simulated eddy variability and the partition of kinetic and potential energy into mean and fluctuating parts is evaluated in section 4. Section 5 then investigates the overall reduction of simulated winter mixed-layer depths found in mid and high latitudes on switching from $1 /{ }^{\circ}$ to $1 /{ }^{\circ}$ horizontal resolution. A concluding discussion ends the paper.

\section{Model description}

The numerical model is based on the Geophysical Fluid Dynamics Laboratory's (GFDL) Modular Ocean Model (MOM: Pacanowski et al. 1991) primitive-equation ocean circulation model, here set up for the equatorial and North Atlantic Ocean between $15^{\circ} \mathrm{S}$ and $65^{\circ} \mathrm{N}$. It is run in two configurations: an eddy-permitting configuration with a horizontal grid spacing of $1 / 3^{\circ}$ in meridional and $2 / 5^{\circ}$ in zonal directions and an eddy-resolving configuration with grid spacing of $1 / 9^{\circ} \times 2 / 11^{\circ}$. Hereafter, the two configurations will be referred to as the $1 / 3$ and $1 / 9^{\circ}$ model, respectively. Both $13^{\circ}$ and $19^{\circ}$ configurations use the same vertical grid with 37 levels of which 11 are placed in the upper $150 \mathrm{~m}$. The bottom topography is taken from the original setup of the $13^{\circ}$ version of the Community Modeling Effort (CME) model (Bryan and Holland 1989). It is based on a high-resolution $\left(1 / 12{ }^{\circ}\right)$ topographic dataset, with no smoothing applied except for removal of all isolated single-point extrema on the $1 / 3$ grid. For the $1 \%^{\circ}$ set up, each grid box of the $1 / 3^{\circ}$ model is simply split into 3 $\times 3$ boxes, thereby ensuring that the bottom topography is identical in both versions. As a consequence, all topographic steps are resolved by at least three grid points in the $19^{\circ}$ model, which may reduce the effect of the noslip condition imposed at lateral walls.

Vertical mixing in and below the surface mixed layer is modelled by the turbulent kinetic energy (TKE) closure of Gaspar et al. (1990) following the implementation of Blanke and Delecluse (1993) except for a higher minimum level of TKE $\left(0.04 \mathrm{~cm}^{2} \mathrm{~s}^{-2}\right)$ chosen to closely match observations of diapycnal diffusion in the main thermocline (Ledwell et al. 1993). Horizontal mixing is parameterized using the highly scale-selective biharmonic operator. In the $1 / 3^{\circ}$ model, horizontal mixing coefficients are set to $A_{m}=A_{h}=2.5 \times 10^{19} \mathrm{~cm}^{4} \mathrm{~s}^{-1}$ for both momentum and tracers, whereas in the $1 /{ }^{\circ}$ model mixing coefficients were slowly reduced over the first two years of integration to values as small as possible to minimize damping of the eddy field while avoiding numerical instabilities. Final mixing coefficients reached by this subjective procedure were $A_{m}=2.8 \times$ $10^{18} \mathrm{~cm}^{4} \mathrm{~s}^{-1}$ for momentum and $A_{h}=0.8 \times 10^{18} \mathrm{~cm}^{4}$ $\mathrm{s}^{-1}$ for tracers, which for both values is very close to those found by Smith et al. (2000) (at 1/10 at the equator). The atmospheric forcing consists of "climatological" monthly mean wind stress and heat flux fields derived from the years 1989 to 1993 of the reanalysis project carried out at the European Centre for Medium-Range Weather Forecasts (ECMWF) (Gibson et al. 1997). Freshwater fluxes are parameterized by restoring surface salinity to observed monthly means taken from the Levitus et al. (1994) atlas. The formulation of the surface heat flux follows Haney (1971), with the downward heat flux into the ocean being expressed as

$Q_{\mathrm{NET}}\left(T_{\text {surf }}\right)=Q_{\mathrm{SOL}}+Q_{\mathrm{NSOL}}+Q_{2}\left(\mathrm{SST}_{\mathrm{obs}}-\mathrm{SST}_{\mathrm{mod}}\right)$

in which $Q_{\mathrm{SOL}}$ and $Q_{\mathrm{NSOL}}$ are solar and nonsolar heat fluxes provided by the ECMWF reanalysis. Absorption of solar radiation in the water column is computed by an empirical biexponential parameterization for clear ocean water (Paulson and Simpson 1977); $\mathrm{SST}_{\mathrm{obs}}$ is the observed weekly sea surface temperature field (Reynolds and Smith 1994) that was also used as boundary condition in the ECMWF reanalysis; and $Q_{2}$ represents the change of the surface heat flux per degree Celsius deviation of the simulated SST from the observed one. It has been computed from the 6-hourly reanalysis fields 
by a linear expansion of the surface heat flux bulk formulae (Barnier et al. 1995).

Northern and southern boundaries are closed as is the Strait of Gibraltar, with buffer zones $1.5^{\circ}$ wide (i.e., 5 grid points in the $13^{\circ}$ model, 15 grid points in the $1 / 9^{\circ}$ one) at which temperature and salinity are restored to monthly mean climatological values with restoring timescales decreasing from 25 days at the innermost grid point to 5 days at the wall. Restoring temperatures and salinities are taken from the Levitus (1982) atlas, except for deep levels in Denmark Strait where conductivitytemperature-depth (CTD) station data are used to account for the signature of Denmark Strait overflow water (Döscher et al. 1994).

Corresponding to the refinement of the horizontal grid, the time step is reduced from about $30 \mathrm{~min}$ in the $13^{\circ}$ model to $10 \mathrm{~min}$ in the $19^{\circ}$ configuration. Hence the ninefold increase in storage space is accompanied by a 27-fold increase in CPU time requirements. Coupled into both configurations of the circulation model is a simple four-component ecosystem model (Oschlies and Garçon 1999) that is not relevant for the results reported below (possible feedbacks from the biology on the model physics via absorption of solar radiation are neglected in the model). The $19^{\circ}$ configuration of the coupled ecosystem-circulation model was integrated on four processors of a Cray SV-1 vector machine, using about 400 MWords core memory and $130 \mathrm{CPU}$ days per simulated year. Because of the considerable computational cost the $19^{\circ}$ model was initialized with a spunup state of the $1 / 3^{\circ}$ model and then integrated for four years, with the biology inserted in the second year. Although the relatively short integration period does not allow the $19^{\circ}$ model reaching dynamic (or even thermodynamic) equilibrium, an investigation of eddy effects on upper ocean physics seems already sensible at this stage. Encouraging in this respect is that an almost stationary kinetic energy level is reached after about two years (Fig. 1) and that the depth of the winter mixed layer (which is one focus of this paper) remains almost unchanged after the second winter. The relatively quick adjustment of the eddy kinetic energy is similar to the results obtained by Smith et al. (2000) (who started their model from rest). However, basin-averaged kinetic energy is less than $30 \mathrm{~cm}^{2} \mathrm{~s}^{-2}$ whereas the $1 / 10^{\circ}$ model of Smith et al. (2000) reaches more than $40 \mathrm{~cm}^{2} \mathrm{~s}^{-2}$. The higher kinetic energy in the latter model can be related to the finer meridional grid spacing of $0.1^{\circ} \cos \phi$ where $\phi$ is latitude. At a latitude of $56^{\circ} \mathrm{N}$ this is already two times finer than the constant meridional spacing of $19^{\circ} \mathrm{em}-$ ployed in the present study. Higher levels of kinetic energy may also result from the high-frequency variability included in the wind forcing used by Smith et al. (2000) in contrast to the monthly mean forcing employed in the present study. Apart from the somewhat finer horizontal resolution and the higher frequency wind forcing, the setup of the $1 / 10^{\circ}$ model by Smith et al. (2000) primarily differs from the one employed here

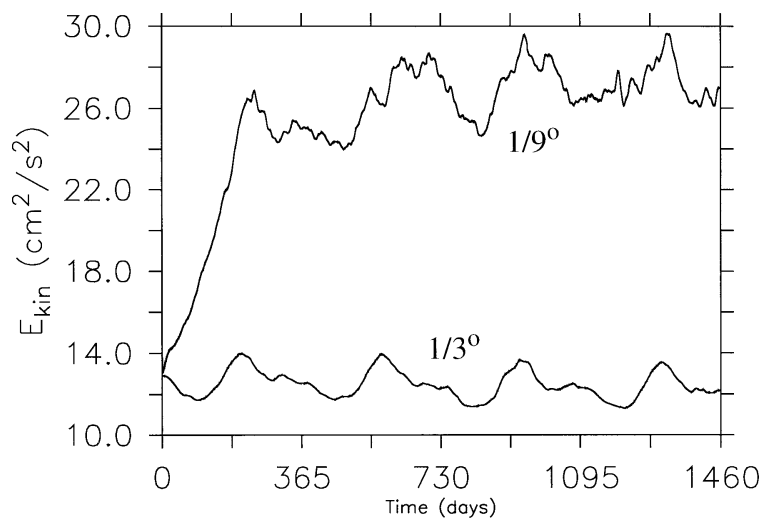

FIG. 1. Evolution of the basin-averaged horizontal kinetic energy for the four years simulated by the $1 / 9^{\circ}$ and $1 / 3^{\circ}$ models, respectively. The annual cycle with a maximum in summer basically indicates the response of the tropical ocean to the seasonal forcing (in particular the retroflection of the North Equatorial Countercurrent). In the subsequent analysis, for each model only the fourth year of the simulation is considered.

in the longer spinup time ( 5 years from Levitus, compared to 3 years from a spunup $13^{\circ}$ state used here), and in the larger model domain, which allows for net flow around Iceland as well as for exchange through the Strait of Gibraltar. The two models also differ in the vertical mixing parameterization (Richardson-number-dependent mixing plus convective adjustment in the Smith et al. model vs a more elaborate TKE closure applied here), which may have some effect on the seasonal cycle of the mixed layer and eventually also on the results reported here. Test experiments with the $1 / 3$ model version, on the other hand, showed relatively little change (small compared to the differences with respect to the $1 \%^{\circ}$ simulation) in the simulated depth of the winter mixed layer when a vertical mixing parameterization similar to that used by Smith et al. was employed.

In the following, results will be shown for the fourth year of the $19^{\circ}$ model run. For comparison, the same single year will be considered for the $13^{\circ}$ run in this study.

\section{Simulated mean transport of volume and heat}

\section{a. Volume transport}

Because the applied wind stress curl is the same in both simulations, linear Sverdrup theory would predict identical vertically integrated volume transport streamfunctions for the two model simulations. Apart from some intensification of the subpolar gyre in the $19^{\circ}$ model, differences between annually averaged streamfunctions are indeed small in the eastern basin. More pronounced differences can be identified near the western boundary, particularly in the Gulf Stream region (Fig. $2)$. The strong ( $\left.>80 \mathrm{~Sv}: \mathrm{Sv} \equiv 10^{6} \mathrm{~m}^{3} \mathrm{~s}^{-1}\right)$ anticyclone off Cape Hatteras, which has been a typical, albeit unrealistic feature in many previous simulations at $13^{\circ}$ and 

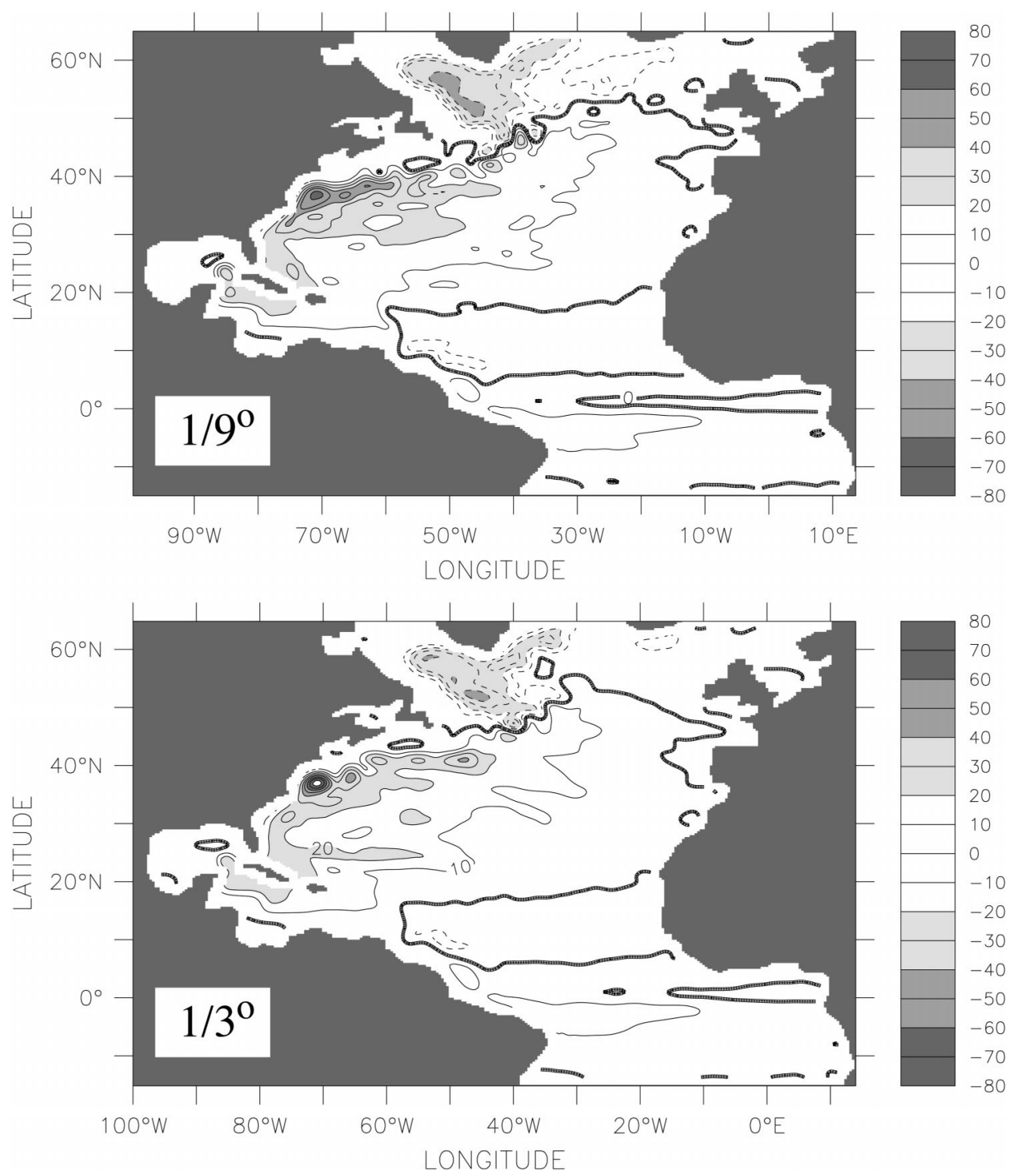

FIG. 2. Annual mean of the vertically integrated transport streamfunction of the $19^{\circ}$ run (top) and the $1 / 3^{\circ}$ run (bottom). Units are $\mathrm{Sv} \equiv 10^{6} \mathrm{~m}^{3} \mathrm{~s}^{-1}$

even $1 \%^{\circ}$ resolution (Beckmann et al. 1994), has essentially disappeared in the $19^{\circ}$ run. However, the Gulf Stream still leaves the coast too far to the north and its transport remains below observational estimates. For example, the annual Eulerian mean transport at $68^{\circ} \mathrm{W}$ increases from $40 \mathrm{~Sv}$ in the $13^{\circ}$ run to $56 \mathrm{~Sv}$ in the $19^{\circ}$ run, which still is only about two thirds of the observational estimate ( $88 \mathrm{~Sv}$ ) by Johns et al. (1995). A better simulation of the Gulf Stream separation and transport was achieved in the $1 / 10^{\circ}$ run of Smith et al. (2000).

Some improvement similar to that found by Smith et al. (2000) can be noted for the region of the so-called "Northwest Corner" of the North Atlantic Current (NAC) between $45^{\circ}$ and $53^{\circ} \mathrm{N}, 40^{\circ}$ and $47^{\circ} \mathrm{W}$ in the $19^{\circ}$ run. On the other hand, neither the $19^{\circ}$ nor the $1 /{ }^{\circ}$ configurations used here show an adequate representation of the Azores Current. Jia (2000) and Özgökmen et al. (2001) suggest a close dynamical relation between Mediterranean outflow and the Azores Current. Differences between the results of the present study and the simulation of the Azores Current in the basin-scale model of Smith et al. (2000) may, in this region, be attributed to the different treatment of the Mediterranean outflow: while the present model uses restoring to climatological temperature and salinity values near the closed Straits of Gibraltar, Smith et al. (2000) explicitly resolved the western part of the Mediterranean and the water exchange through the Straits of Gibraltar.

\section{b. Surface heat flux}

The degree of realism reached by the simulated upper ocean heat budget can be assessed by evaluating the 


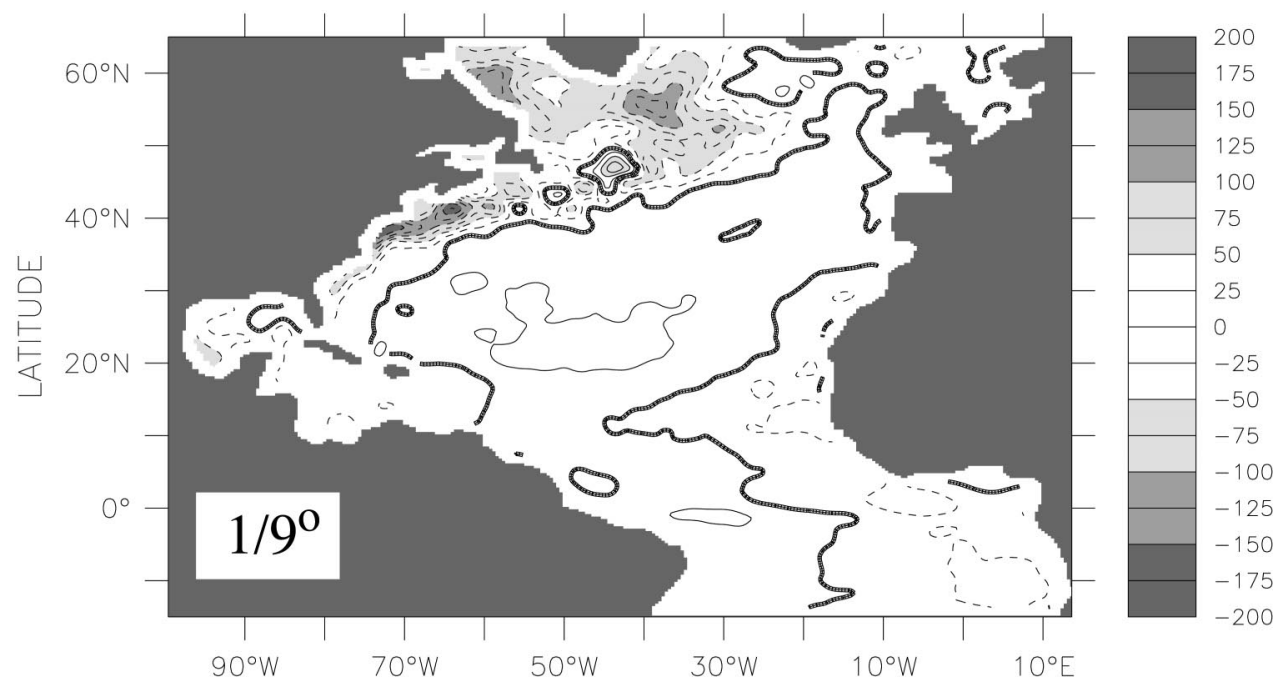

LONGITUDE

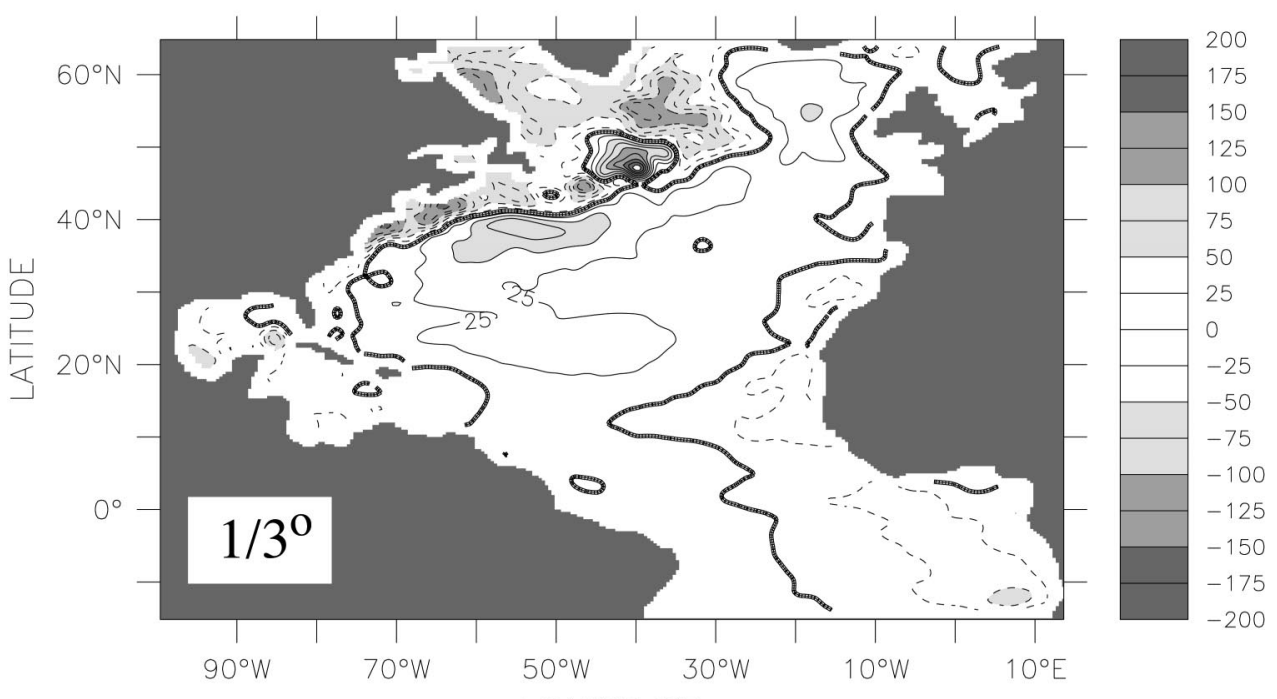

LONGITUDE

FIG. 3. Annual mean of the correction term $Q_{2}\left(\mathrm{SST}_{\mathrm{obs}}-\mathrm{SST}_{\mathrm{mod}}\right)$ for the surface heat flux [Equation (1)] for the $1{ }^{\circ}$ run (top), and the $1 / 3^{\circ}$ run (bottom). Units are $\mathrm{W} \mathrm{m}^{-2}$.

flux correction term $Q_{2}\left(\mathrm{SST}_{\mathrm{obs}}-\mathrm{SST}_{\text {mod }}\right)$ by which the simulated surface heat flux deviates from that provided by the ECMWF reanalysis project [Eq. (1)]. The simulated heat flux (into the ocean) exceeds that diagnosed from the ECMWF data whenever the SST is underestimated by the model (and vice versa), typical values of the coefficient $Q_{2}$ being $25-50 \mathrm{~W} \mathrm{~m}^{-2} \mathrm{~K}^{-1}$.

Overall, annual mean flux corrections turn out to be somewhat smaller in the $1 / 9$ simulation compared to the $1 / 3^{\circ}$ run, with basin-averaged rms values of 33 and 37 $\mathrm{W} \mathrm{m} \mathrm{m}^{-2}$, respectively. Because even a statistically "perfect" model will display phase errors, for example of individual eddies, this rms error will not converge to zero. In addition, there may be a contribution from errors in the ECMWF reanalysis heat-flux data, which have zonally averaged rms uncertainties of about $20 \mathrm{~W} \mathrm{~m}^{-2}$ in the Northern Hemisphere (e.g., Trenberth et al. 2001). As a rough estimate of the residual rms error, which may be expected for "perfect" atmospheric forcing data and a hypothetical "perfect" model, the rms heat flux difference between two consecutive model years (years 3 and 4 ) of the climatologically forced $19^{\circ}$ simulation was computed. Because of the neglect of possible errors in the surface forcing data the resulting residual rms error of $11 \mathrm{~W} \mathrm{~m}^{-2}$ is probably a low estimate, indicating that switching model resolution from $13^{\circ}$ to $19^{\circ}$ can reduce the nonresidual rms error by at least $15 \%$. As shown below, this reduction occurs mainly at mid and high latitudes where it reaches about $25 \%$ (Fig. 4).

A reduction of the flux correction term is most pronounced near the Gulf Stream and the northwest corner of the NAC (Fig. 3), as may be expected from the above 
mentioned changes in the simulated volume transport. An additional region over which the flux correction is considerably reduced in the $19^{\circ}$ simulation is the eastern subpolar North Atlantic. Section 5 will show that this apparent improvement can at least partly be explained by eddy-induced changes in upper ocean stratification.

Qualitatively similar to the $1 / 3^{\circ}$ model, the $1 / 9^{\circ}$ model tends to require more heat input than provided by the ECMWF reanalysis in the subtropics, while the model requires enhanced cooling over the western part of the subpolar gyre. This is equivalent to simulated SSTs being slightly too cold in the subtropics (by less than $0.5^{\circ} \mathrm{C}$ ) and too warm in the western part of the subpolar gyre (by up to $1^{\circ}-2^{\circ} \mathrm{C}$ ). To the extent the ECMWF heat fluxes can be assumed to be correct, this discrepancy would have to be explained by deficiencies of the ocean model. Apart from an underprediction of marine stratocumulus by the ECMWF reanalysis off the west coast of Africa (Jakob 1999), that can lead to overly large solar heat input and subsequent overestimation of oceanic SSTs in this region, the role of errors in the ECMWF reanalysis data in explaining discrepancies between simulated and observed SSTs is not yet clear. Trenberth et al. (2001) compared the ECMWF reanalysis product with the da Silva et al. (1994) surface heatflux climatology based on ship data and bulk formulae. Their results indicate that oceanic heat loss in the ECMWF data is too low by some $30 \mathrm{~W} \mathrm{~m}^{-2}$ over the western and central parts of the subpolar North Atlantic. On the other hand, overly warm surface waters in the western part of the subpolar gyre of the model may instead be related to the imposed closed northern wall that prevents any circulation around Iceland and leads to a too far western position of the NAC. Too cold surface waters in the subtropical gyre could, on the other hand, indicate overly high diapycnal mixing in the model. Although the model's vertical diffusivities in the thermocline were tuned to closely match the observations of Ledwell et al. (1993) in the eastern part of the subtropical gyre, diapycnal mixing may also be caused by horizontal mixing across sloping isopycnals or by enhanced diffusion resulting from numerical dispersion effects of the centered-differences advection numerics.

Zonally and annually averaged surface heat fluxes for both model configurations as well as for the ECMWF 1989-93 reanalysis are displayed in Fig. 4 together with rms values of the annual flux corrections for each latitude band. Differences between simulated heat fluxes and those deduced from the ECMWF reanalysis are small south of about $37^{\circ} \mathrm{N}$, where zonally averaged differences amount to less than $10 \mathrm{~W} \mathrm{~m}^{-2}$ and zonally computed rms values are smaller than $30 \mathrm{~W} \mathrm{~m}^{-2}$. Farther north, where both models simulate heat losses that exceed the ECMWF reanalysis data by up to $40 \mathrm{~W} \mathrm{~m}^{-2}$ in the zonal average, model - data differences amount to about 50 $\mathrm{W} \mathrm{m} \mathrm{m}^{-2}$ in the zonal rms sense. That both models simulate a larger oceanic heat loss over the subpolar North Atlantic than the ECMWF reanalysis data may to a large extent be explained by the probably underestimated heat loss in the ECMWF data (Trenberth et al. 2001). Interestingly, the $19^{\circ}$ model needs, in the zonal average, a greater heat flux correction than the $13^{\circ}$ simulation, whereas the reverse is the case when regarding the zonal rms (Fig. 4). This apparent discrepancy can be explained by the better simulation of the Northwest Corner of the NAC that considerably reduces the excessive local heating required in the $1 / 3^{\circ}$ simulation (Fig. 3).

Overall, the discrepancies between applied and fluxcorrected surface heat fluxes are considerably smaller than reported for earlier high-resolution modeling studies [e.g., the $1 /{ }^{\circ}$ Dynamo group experiments (Willebrand et al. 2001) or the $1 / 10^{\circ}$ simulation of Smith et al. 2000)]. Features that can help explain this seeming improvement include the use of ECMWF reanalysis forcing fields for the 5-yr period 1989-93 rather than fields taken from the ECMWF forecast model over the 3-yr period 1986-88 that were used in both the Dynamo experiments and the $1 / 10^{\circ}$ simulation of Smith et al. (2000). A better agreement between simulated and observed SSTs can to some extent also be attributed to the turbulence closure scheme applied, as has been demonstrated by Blanke and Delecluse (1993) for the tropical Atlantic in comparison to a simpler Richardsonnumber-dependent parameterization used by Smith et al. (2000). (The Dynamo experiments used either a Kraus-Turner type or no mixed layer model at all.)

Evidently, the short integration time of a few years to decades does not allow either model to reach thermodynamic equilibrium. Therefore, all conclusions about the accuracy of simulated heat budgets must be regarded with some caution. For the models presented here, the basin-averaged temperature decreases by $0.005^{\circ}$ and $0.001^{\circ} \mathrm{C}$ per year in the $19_{9}^{\circ}$ and $13^{\circ}$ runs, respectively, corresponding to an average cooling of 2.3 and $0.5 \mathrm{~W} \mathrm{~m}^{-2}$ in the two experiments. Although much smaller than the annual differences between the two models' surface heat fluxes, such imbalances could eventually add up and exert a feedback on the simulated fluxes of heat in the model.

\section{c. Meridional heat transport}

In the absence of significant local heat storage in the ocean, the annual mean air-sea heat flux must be balanced by a divergence of the annually averaged lateral heat transport. Figure 5a shows that at all latitudes the northward heat transport simulated by the $1 /{ }^{\circ}$ model exceeds that of the $13^{\circ}$ simulation. At $25^{\circ} \mathrm{N}$, for example, it increases by more than $20 \%$ from $0.89 \mathrm{PW}$ in the eddy-permitting $13^{\circ}$ run to $1.15 \mathrm{PW}$ in the eddy-resolving $19^{\circ}$ experiment, the latter value being closer to observational estimates (e.g., $1.07 \pm 0.26 \mathrm{PW}$ by Macdonald 1998). As shown by the lower curves in Fig. 5a, the eddy component of the meridional heat transport is small in both model configurations and is southward in the subtropics and northward to the north of about $35^{\circ} \mathrm{N}$, 

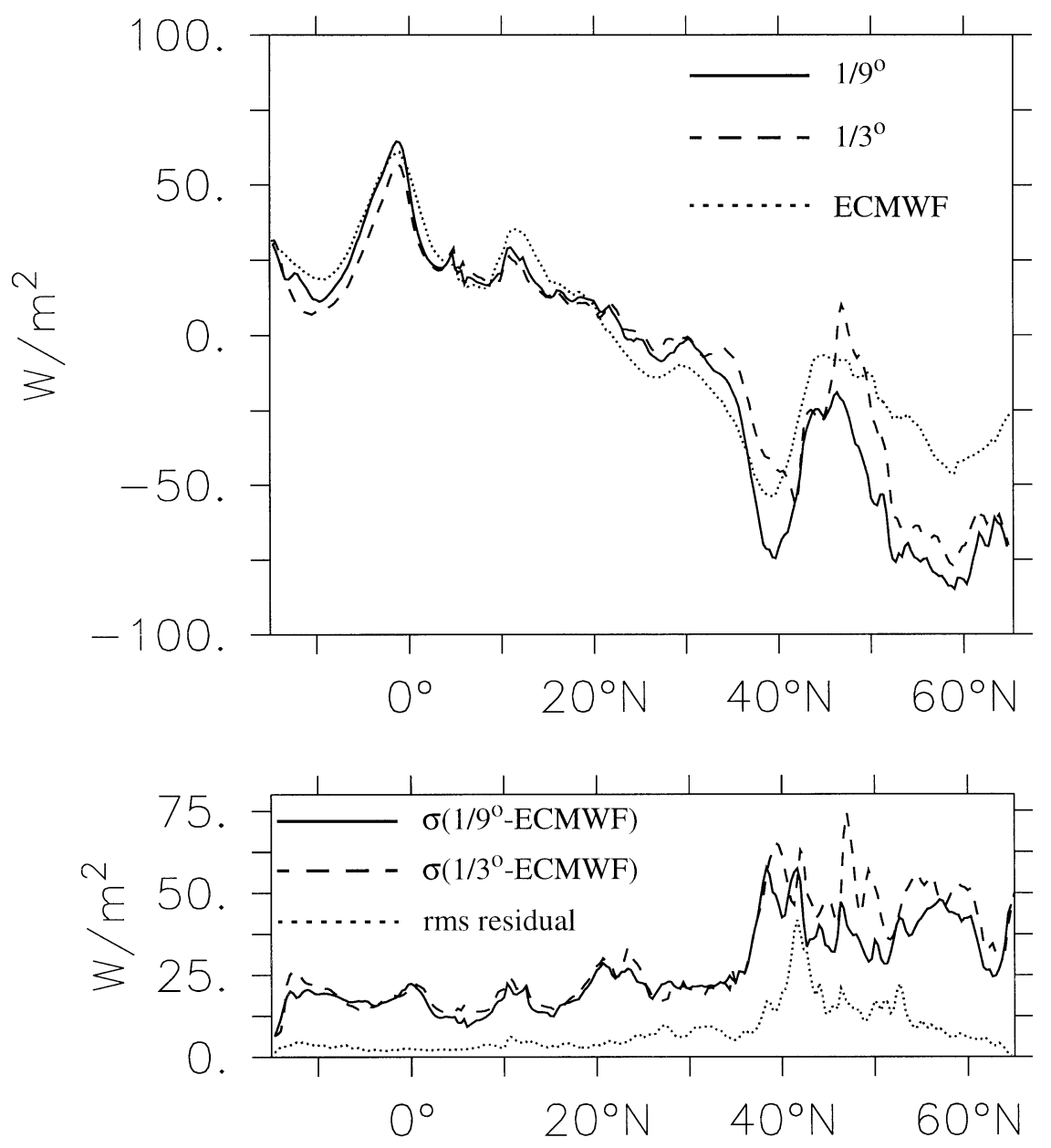

FIG. 4. Top: Zonal mean of the annual surface heat flux into the ocean as derived from the ECMWF reanalysis for the 5-yr period 1989-93 (dotted) and diagnosed from the $19^{\circ}$ run (solid) and $1 / 3^{\circ}$ run (dashed). Bottom: Standard deviation of the difference between model heat flux and ECMWF reanalysis heat flux for each latitude band. The dotted is the rms difference between surface heat fluxes diagnosed from the two climatologically forced consecutive model years 3 and 4 , which gives a rough estimate for the residual rms error expected even for a perfect model.

in good agreement with previous studies (Beckmann et al. 1994; Smith et al. 2000). With the exception of the latitude range of $38^{\circ}-48^{\circ} \mathrm{N}$, where eddies transport more heat (by up to $0.1 \mathrm{PW}$ ) northward in the high-resolution model, the average meridional heat transport by eddies is relatively insensitive to the model's resolution despite large changes in eddy activity (see section 4). A similar result was reported by Beckmann et al. (1994) for their comparison of a $1 / 3^{\circ}$ and a $16^{\circ}$ model. With eddies moving water predominantly along isopycnals, eddy heat transport can become significant, mainly in regions with substantial temperature gradients along isopycnal surfaces (Bryan 1986) or near the sea surface where eddy-induced temperature anomalies can nonadiabatically interact with the air-sea heat flux (Drijfhout 1994). A closer analysis of the $19^{\circ}$ model results reveals that the northward heat transport by eddies between $38^{\circ}$ and $48^{\circ} \mathrm{N}$ takes place mainly in the Gulf Stream region close to the sea surface. This suggests a dominant role of airsea interaction associated with SST anomalies to either side of the approximately zonally oriented mean current.

Earlier studies of the $13^{\circ} \mathrm{CME}$ configuration showed that the meridional heat transport was intimitely related to the thermohaline forcing applied in the northern buffer zone (Döscher et al. 1994). In particular, an increase in the northward heat transport within the northern buffer zone translated to an increase of approximately the same magnitude at all latitudes. When comparing results from the $19^{\circ}$ and the $1 / 3^{\circ}$ model configurations, the pattern is different: relatively small $(<0.05 \mathrm{PW})$ differences in simulated meridional heat flux within the $1.5^{\circ}$ wide northern and southern buffer zones (with restoring timescales and temperatures and salinities being the same for both model configurations) are accompanied by much larger differences $(>0.25 \mathrm{PW})$ at mid latitudes. As can be seen from the decomposition of the simulated 

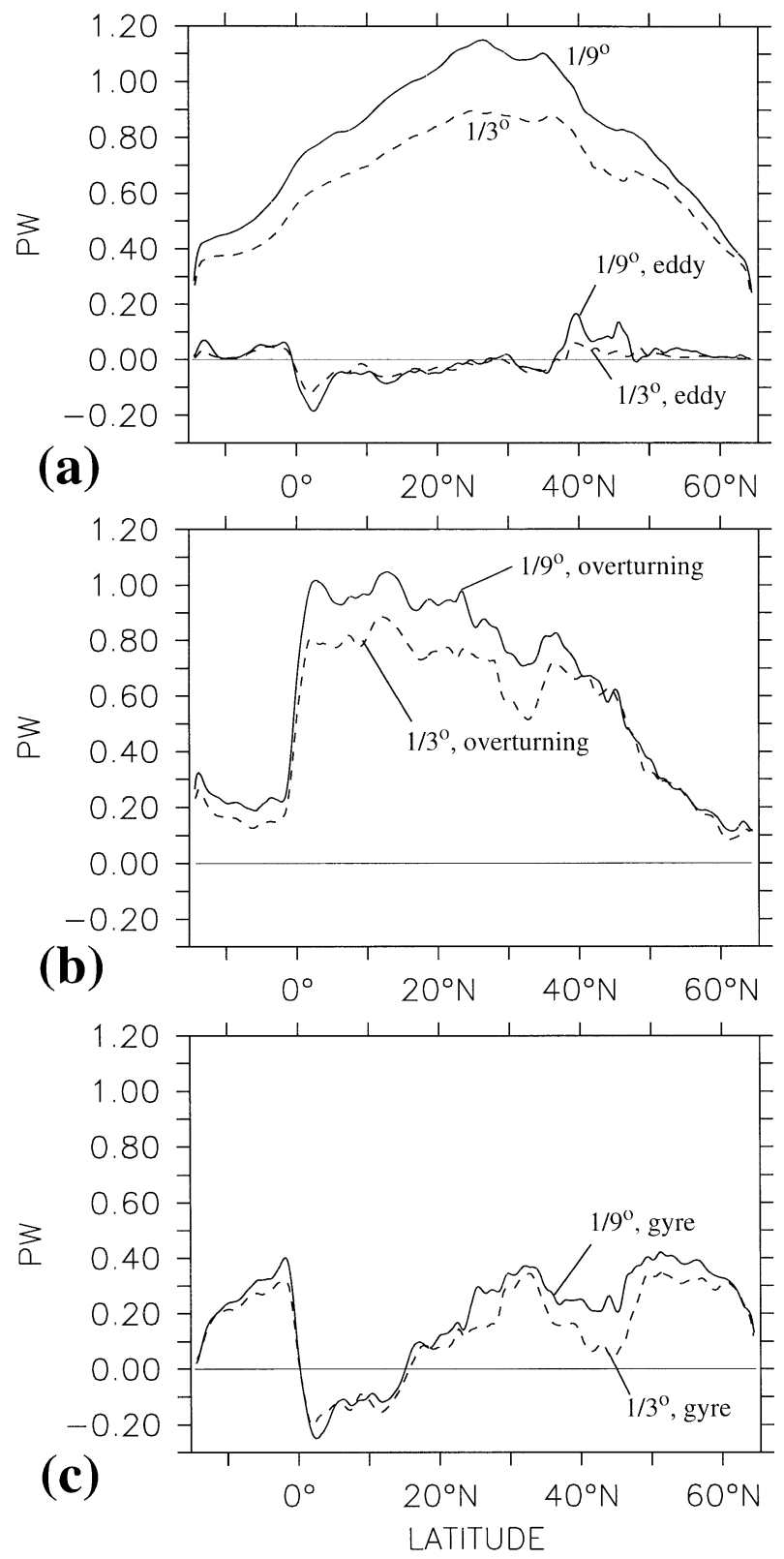

FIG. 5. (a) Meridional heat transport in the $19^{\circ}$ run (solid) and $1 / 3$ run (dashed), respectively. The upper curves show the total annual mean heat transport due to advection, the lower curves show the eddy components. The heat transport associated with biharmonic diffusion is extremely small (order $10^{-3} \mathrm{PW}$ ) in both models. (b) Meridional overturning component of the meridional heat transport (zonally averaged temperature times zonally averaged velocity). (c) Horizontal gyre component of the meridional heat transport [difference (a) minus (b)]. Units are $\mathrm{PW}=10^{15} \mathrm{~W}$. meridional heat flux into overturning and horizontal gyre components (Figs. 5b,c), the increase in northward heat transport is dominated by the gyre component to the north of about $40^{\circ} \mathrm{N}$ and by the overturning component further south.

The enhanced northward heat transport by the gyre component is consistent with the increase in the cyclonic circulation of the subpolar gyre in the $19^{\circ}$ simulation (Fig. 2). The increase in the overturning component of the heat transport with refined grid resolution, on the other hand, relates to an increase in the meridional overturning circulation associated with the North Atlantic Deep Water in the subtropics (not shown). Böning et al. (1995) identified unrealistically high diapycnal mixing by the horizontal mixing operator across sloping isopycnals in the Gulf Stream region as a major source for the strong upwelling in this latitude range in the $1 /{ }^{\circ} \mathrm{CME}$ model (and also in the coarser $1^{\circ}$ version). For adequate eddy parameterizations, they could show substantial improvement in the simulated meridional heat transport that, for the coarse-resolution $1^{\circ}$ model, reached similar levels as the $1 \%^{\circ}$ simulation reported here. The decrease in the horizontal mixing coefficients made possible by the finer $1 /{ }^{\circ}$ grid, together with the choice of the horizontal viscosity being larger than the horizontal diffusivity (section 2), reduces the spurious upwelling and results in a stronger meridional overturning in midlatitudes in the $1 \%^{\circ}$ run.

\section{Simulated eddy variability}

\section{a. Sea surface height}

Via the direct relation between geostrophic surface velocities and sea surface height (SSH) gradients, satellite altimetry can provide synoptic descriptions of the global ocean's surface eddy field. Here, a blended dataset of the TOPEX/Poseidon and ERS-1 altimeters (Le Traon and Ogor 1998; Le Traon et al. 1998) is used to evaluate the SSH variability simulated by both eddy-resolving and eddy-permitting models (Fig. 6). Simulated SSH variability is higher in the eddy-resolving $1 /{ }^{\circ}$ model than in the eddy-permitting $13^{\circ}$ run almost everywhere north of about $10^{\circ} \mathrm{N}$. Overall, the amplitude of the observed SSH variability is reproduced rather well by the $1 / 9^{\circ}$ run whereas the $1 / 3$ simulation reveals a systematic underestimation. However, in both models simulated variability tends to be lower than observed in the eastern North Atlantic, a region of very low SSH variability (a few centimeters rms). Part of this discrepancy can be related to the model's large-scale underestimation of the amplitude of the annual SSH cycle by one to two centimeters (Ferry

FIG. 6. Rms sea surface height variability simulated by (a) the $1 /{ }^{\circ}$ model, (b) the $13^{\circ}$ model, and (c) altimeter data from the TOPEX/ Poseidon and ERS-1 satellites for the year 1993 (Le Traon and Ogor 1998; Le Traon et al. 1998). The seasonal cycle of the basin-averaged surface height has been substracted in all maps. Maxima that are visible in the altimeter data in some coastal regions like the North Sea and off the South American coast near the equator are probably due to residual errors in the tidal model (units are $\mathrm{cm}$ ). 

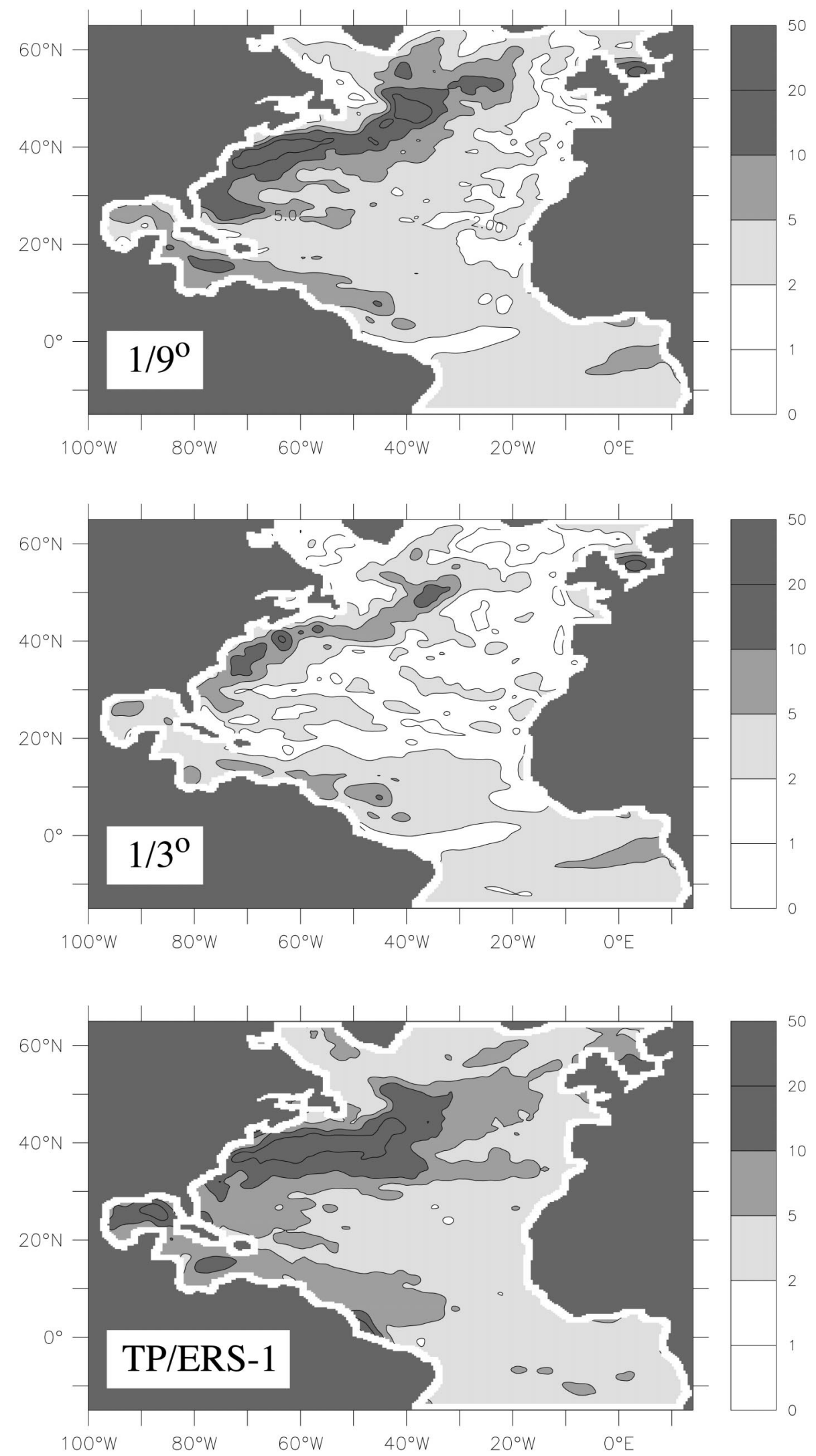

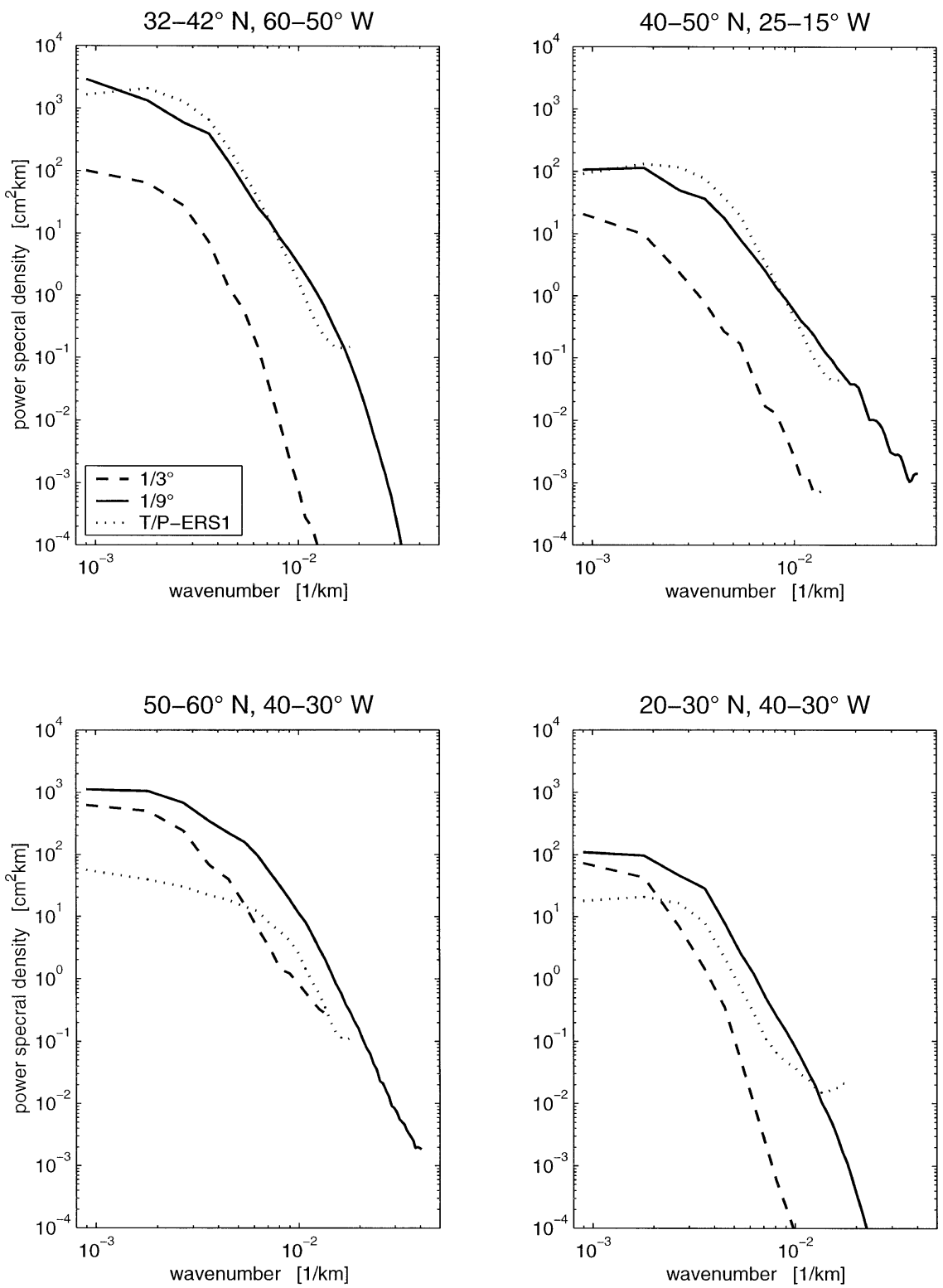

FIG. 7. Spectra of the spectral energy density of meridional sea surface height variations averaged of $10^{\circ} \times 10^{\circ}$ boxes: (a) Gulf Stream region, (b) midlatitude eastern North Atlantic, (c) Irminger Sea, and (d) subtropical gyre.

et al. 2000). Possible explanations for this underestimation are errors in the ECMWF heat flux data and effects of the global hydrological cycle on the observed SSH that are not included in the model.

Areas of high SSH variability are, in the open ocean, in general associated with strong mean currents. As a consequence, one can immediately link major discrepancies between the spatial patterns of simulated and observed SSH variability to model deficiencies in correctly positioning mean current systems. For example, the model's Gulf Stream is slightly too far north as is the associated SSH variance. Similarly, the SSH variability in the $19^{\circ}$ simulation (and to a lesser degree also in the $13^{\circ}$ one) is too high in the Irminger Sea, which is related to the too far western position of the model's NAC. Furthermore, simulated SSH variability is too low in the eastern basin particularly near $35^{\circ} \mathrm{N}$ where both model configurations fail to reproduce the Azores Current.

Because the geostrophic surface currents are related to $\mathrm{SSH}$ gradients, they are sensitive to the spatial scales of the individual SSH anomalies. To examine whether the simulated SSH variability occurs at spatial scales similar to those observed by altimetry, spatial SSH spectra are examined in selected $10^{\circ} \times 10^{\circ}$ boxes. In the Gulf Stream region (Fig. 7a) as well as in the mid- 

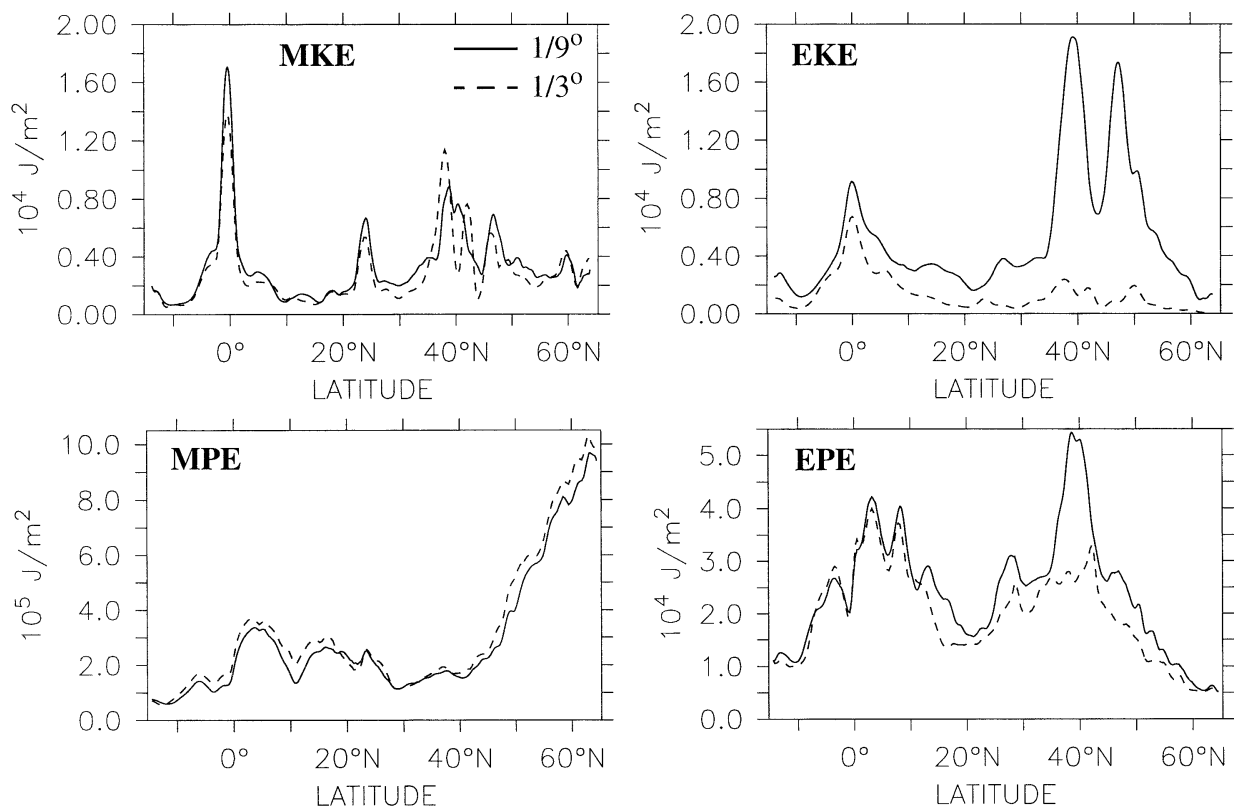

FIG. 8. Zonal average of mean kinetic energy (MKE), eddy kinetic energy (EKE), mean available potential energy (MPE), and eddy available potential energy (EPE) integrated over the upper $1000 \mathrm{~m}$. Solid lines refer to the $19^{\circ}$ run, dashed lines to the $1 / 3^{\circ}$ simulation. EKE and EPE include all deviations from the annual mean. Note the different energy scales in different panels.

latitudinal eastern North Atlantic (Fig. 7b) the $1 \%^{\circ}$ simulation reproduces the spatial SSH spectra derived from the blended TOPEX/Poseidon and ERS-1 altimeter dataset very closely. This is in contrast to the $13^{\circ}$ simulation that in the same regions underestimates $\mathrm{SSH}$ variance at all scales by almost an order of magnitude. In the Irminger Sea (Fig. 7c), however, spectral energy density is overestimated by both model versions, reflecting the wrong placement of the NAC by the model. In the center of the subtropical gyre (Fig. 7d) the $1 /{ }^{\circ}$ model is again closer to the spectra derived from the altimetric dataset. Note, that in this region the spectral energy density of the $\mathrm{SSH}$ field simulated by the $1 \%^{\circ}$ model is somewhat higher than that computed from the mapped altimeter data. The fact that in the same region the model underestimates total rms SSH variability (Fig. 6) must therefore be attributed to wavelengths larger than $5^{\circ}$. A likely example is the model's failure to fully reproduce the large-scale annual SSH cycle (Ferry et al. 2000).

\section{b. Eddy kinetic energy}

As has been reported in previous studies (e.g., Böning and Budich 1992), the increase in basin-averaged kinetic energy that takes place when switching from an eddypermitting to an eddy-resolving model (Fig. 1) can almost entirely be attributed to an increase in eddy kinetic energy (EKE) rather than in mean kinetic energy (MKE). Here, the basin-averaged kinetic energy of the mean flow increases by less than $20 \%$ from $8.6 \mathrm{~cm}^{2} \mathrm{~s}^{-2}$ in the $13^{\circ}$ run to $10.2 \mathrm{~cm}^{2} \mathrm{~s}^{-2}$ in the $19^{\circ}$ simulation, whereas the eddy kinetic energy (here defined as the energy of all deviations from the annual mean flow and computed from 3-daily snapshots of the respective 1-yr analysis phases) increases by almost a factor of 4 from $4.6 \mathrm{~cm}^{2} \mathrm{~s}^{-2}$ in the eddy-permitting model to $17.5 \mathrm{~cm}^{2}$ $\mathrm{s}^{-2}$ in the eddy-resolving version. The zonal averages of MKE and EKE integrated over the upper $1000 \mathrm{~m}$ for the two model configurations reveal that the $19^{\circ}$ model simulates slightly higher levels of MKE in the tropics and subtropics (Fig. 8). In contrast, EKE is larger in the finer resolution model by about an order of magnitude in mid latitudes. As a consequence, EKE values exceed those of MKE almost everywhere in the $19^{\circ}$ simulation, while the reverse is true for the eddy-permitting $13_{3}^{\circ}$ run.

Since the surface wind stress as external source of kinetic energy is the same in both models, the increase in kinetic energy with finer resolution must draw on energy reservoirs within the (simulated) ocean, of which the gravitational potential energy is most readily accessible for conversion into kinetic energy. In the following, only that part of the potential energy that is, in principle, available for conversion into kinetic energy is considered. Neglecting very small contributions of the internal energy, the available potential energy can be defined as the difference in gravitational potential energy with respect to an isentropically leveled state (Reid et al. 1981),

$$
E_{\text {pot,avail }}=-\frac{g}{2} \int \frac{(\rho-\tilde{\rho})^{2}}{d \tilde{\rho} / d z} d z
$$

where $\rho(x, y, z, t)$ is the in situ density, $\tilde{\rho}(z)$ is the horizontally averaged mean density, and $d \tilde{\rho} / d z$ is its statical stability. 

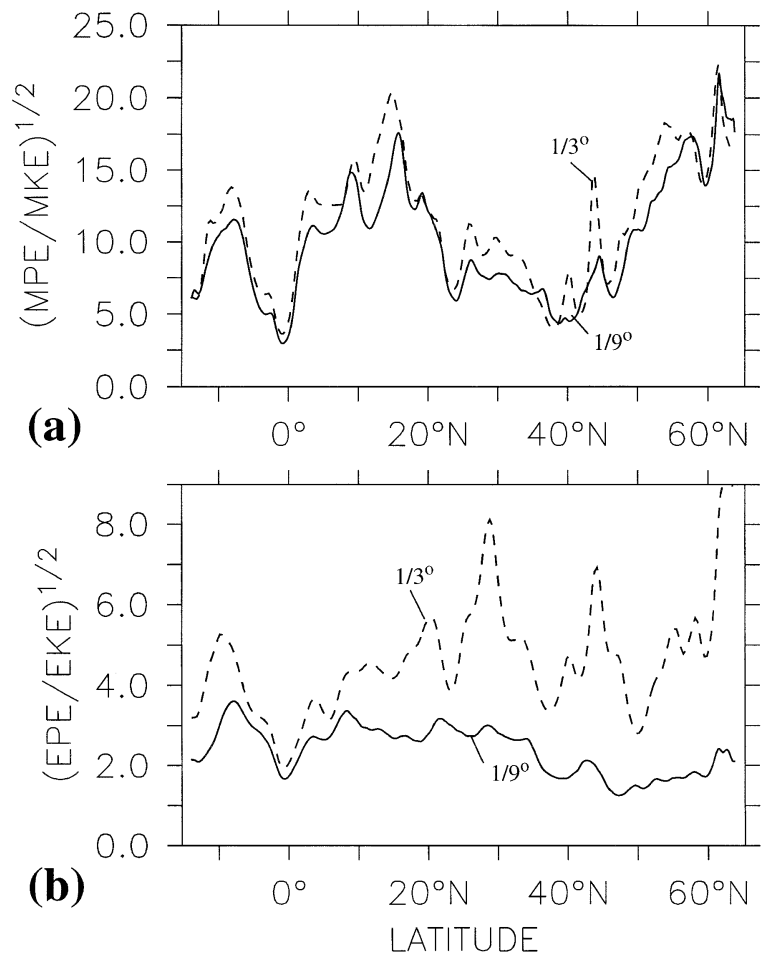

FIG. 9. (a) Ratio of (MKE/MPE) $)^{1 / 2}$ where MKE is mean kinetic energy, MPE is mean potential energy, both of which are zonally averaged and meridionally smoothed by a $2^{\circ}$ boxcar filter. This ratio corresponds to $L / L_{D}$, where $L$ is the scale of the geostrophic mean flow, and $L_{D}$ is the Rossby radius of deformation. (b) Ratio of (EKE/ EPE $)^{1 / 2}$ where EKE and EPE are eddy kinetic energy and eddy potential energy, respectively. The same averaging is applied as in (a).

Zonal averages of mean available potential energy (MPE) and eddy available potential energy (EPE) integrated over the top $1000 \mathrm{~m}$ are displayed in the bottom panels of Fig. 8. At almost all latitudes, MPE is lower in the $19^{\circ}$ run compared to the $13^{\circ}$ simulation, with differences being largest (typically 10\%) in the Tropics and north of about $40^{\circ} \mathrm{N}$. A reduction in MPE with refined resolution, which corresponds to a mean flattening of isopycnal slopes and thus an overall increase in stratification, has also been found in previous studies using idealized model geometries (Böning and Budich 1992).

Resolution dependent changes in the ratio of MPE to MKE, which corresponds to $\left(L / L_{D}\right)^{2}$ where $L$ is the scale of the geostrophic mean flow and $L_{D}$ is the Rossby radius of deformation (e.g., Pedlosky 1979), are relatively small $(\sim 10 \%)$ as shown in Fig. 9 for zonally averaged energies. This is consistent with little differences in the scales of the mean flow among the two model config- urations (cf. Fig. 2). On the other hand, the corresponding expression for eddy length scales, (EPE/EKE) $)^{1 / 2}$, decreases by more than a factor 2 when switching from $1 / 3$ to $1 / 9$ resolution (Fig. 9). Interestingly, the latter ratio shows only little latitudinal variation in the $19^{\circ}$ simulation whereas it tends to increase toward higher latitudes in the $13^{\circ}$ run. Such a behavior can be reconciled with the altimeter data analysis presented by Stammer and Böning (1992), who on the one hand suggested a universal relation of eddy scales with the Rossby radius and on the other hand showed that eddy length scales in the $1 / 3^{\circ}$ model were increasingly overestimated at higher latitudes.

\section{Winter mixed layer depths}

The depth reached by convective overturning in mid and high latitudes in winter is of particular importance for water mass formation and modification, for the invasion of atmospheric trace gases, and for the nutrient supply to the upper-ocean photic zone. Although identical initial conditions and surface forcing fields are used in the two model configurations, it turns out that in most regions north of about $35^{\circ} \mathrm{N}$ the winter mixed layer is shallower in the $19^{\circ}$ model compared to the $1 / 3^{\circ}$ run (Fig. 10). This phenomenon is most pronounced over the eastern part of the subpolar North Atlantic and will be of particular interest for comparison of the ecosystem model component with time series and process-study data in this region, namely at the site of the North Atlantic Bloom Experiment (NABE: $47^{\circ} \mathrm{N}, 20^{\circ} \mathrm{W}$ ) and at Ocean Weather Station India (OWS I: $59^{\circ} \mathrm{N}, 19^{\circ} \mathrm{W}$ ). At these sites, the depth of the winter mixed layer is reduced from about $600 \mathrm{~m}$ (NABE) and $1200 \mathrm{~m}$ (OWS I) in the $1 / 3$ simulation to $370 \mathrm{~m}$ (NABE) and $700 \mathrm{~m}$ (OWS I) in the $19^{\circ}$ experiment, respectively, with the shallower values being in much better agreement with observations (Fig. 11). Although the observations do not fully cover the period of deepest mixing at the NABE site, simultaneous oxygen measurements indicate that winter mixing in these years did not exceed $400 \mathrm{~m}$ (Koeve 2001). Near the location of the Bermuda Atlantic Time Series Study (BATS: $32^{\circ} \mathrm{N}, 65^{\circ} \mathrm{W}$ ), the reduction in the depth of the winter mixed layer with increasing horizontal resolution amounts to a few tens of meters. Here, both models agree with the BATS data within the observed levels of interannual variability (Michaels and Knap 1996). Note that the winter mixed layer depth simulated by the $1 / 9{ }^{\circ}$ model displays much larger temporal variability than that of the $13^{\circ}$ run. As neither simulation includes daily atmospheric forcing, this indicates enhanced mesoscale variability in the eddy-resolving ex-

FIG. 10. Winter mixed layer depth, defined as the maximum depth reached by the mixed layer during the $1-\mathrm{yr}$ simulation of (a) the $1 /{ }^{\circ}$ model and (b) for the $13^{\circ}$ model. The zonal average of the winter mixed layer is shown for both models in (c). The mixed layer depth is defined by a density criterion $\left(\Delta \sigma=0.01 \mathrm{~kg} \mathrm{~m}^{-3}\right)$. Units are meters. 

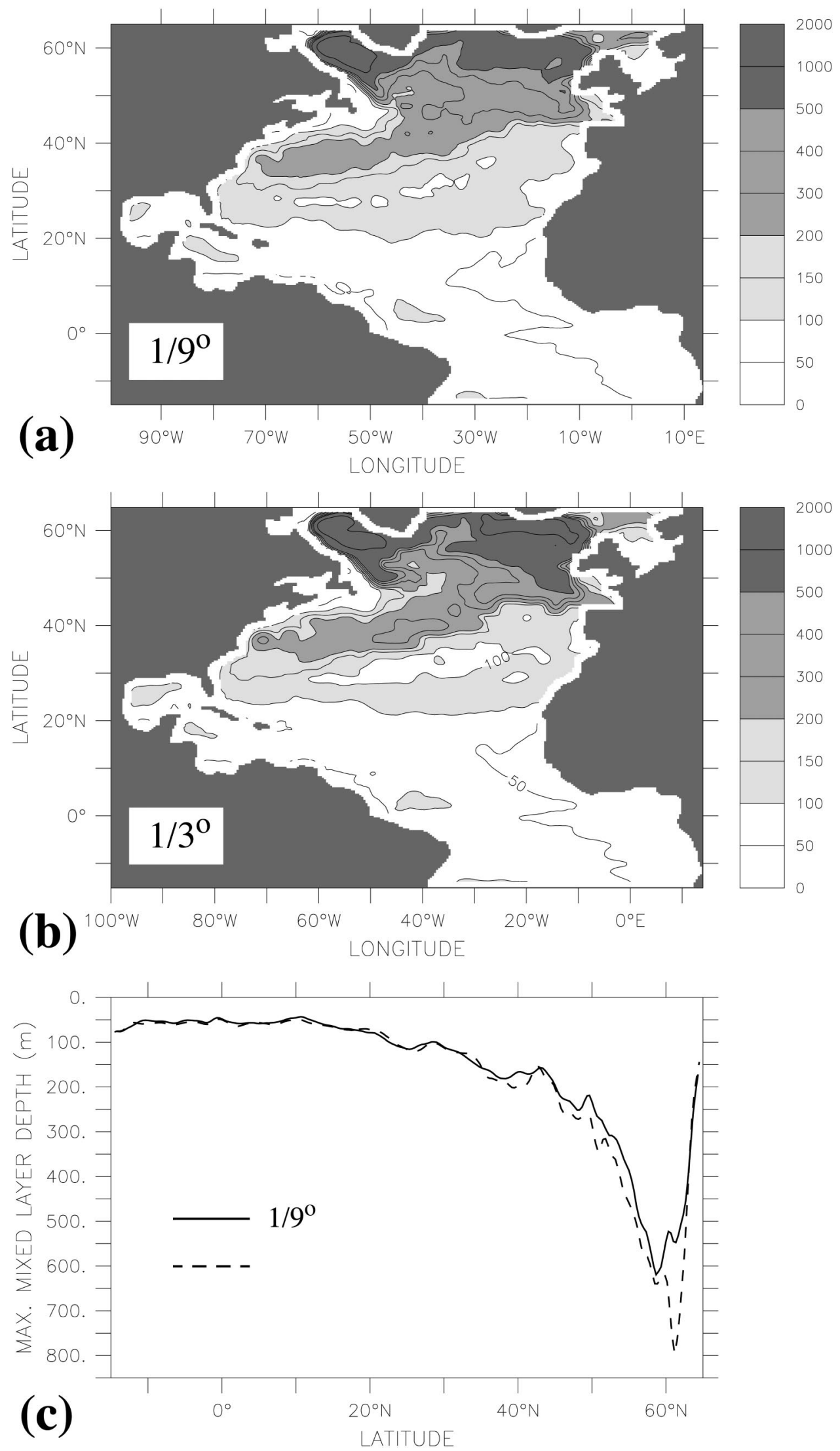


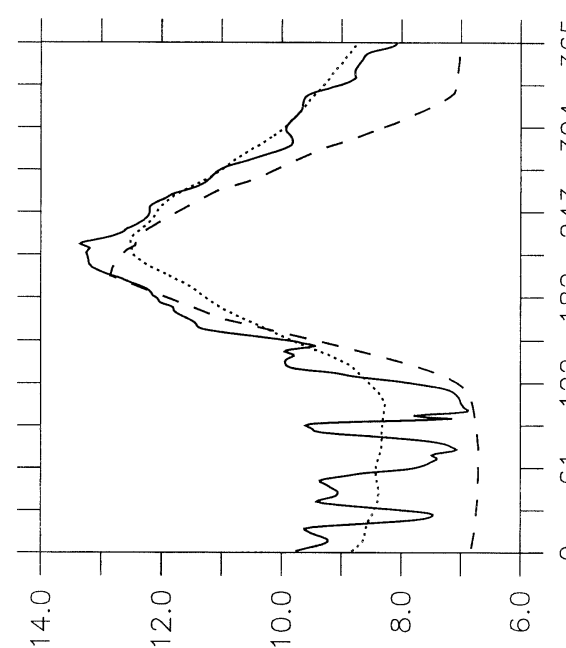

(Jo) ISS

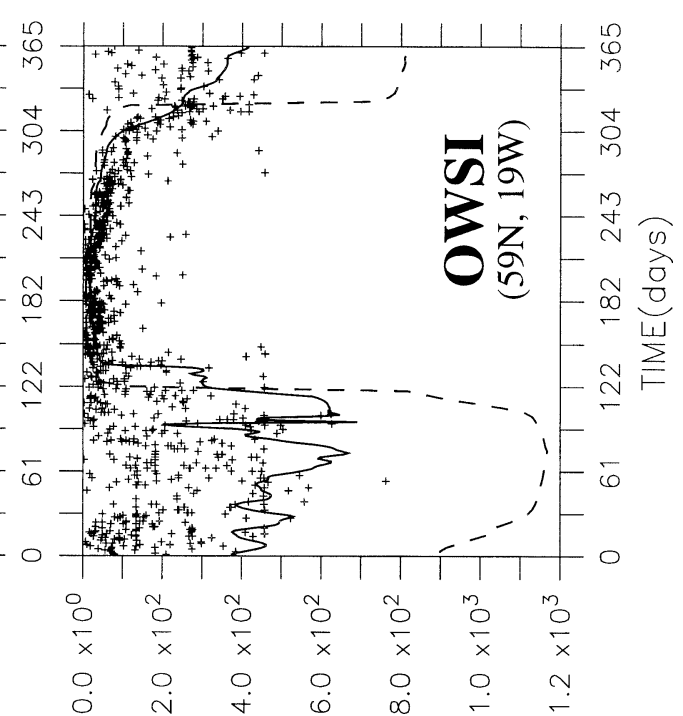

(m) $H \perp d \exists O$

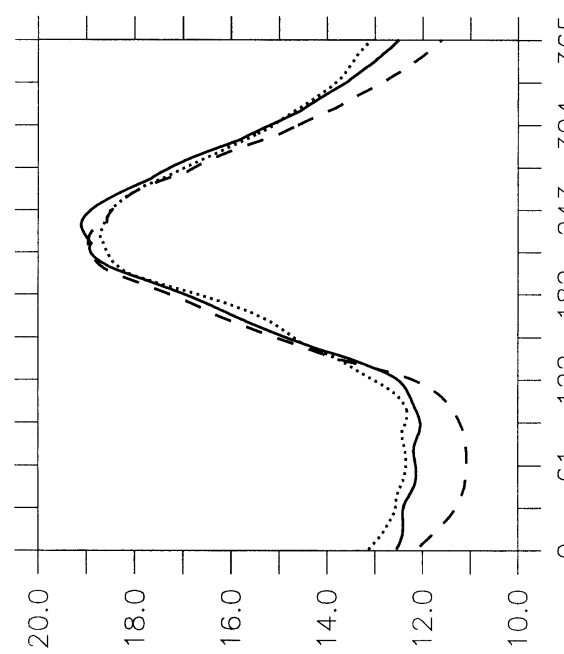

(Jo)LSS

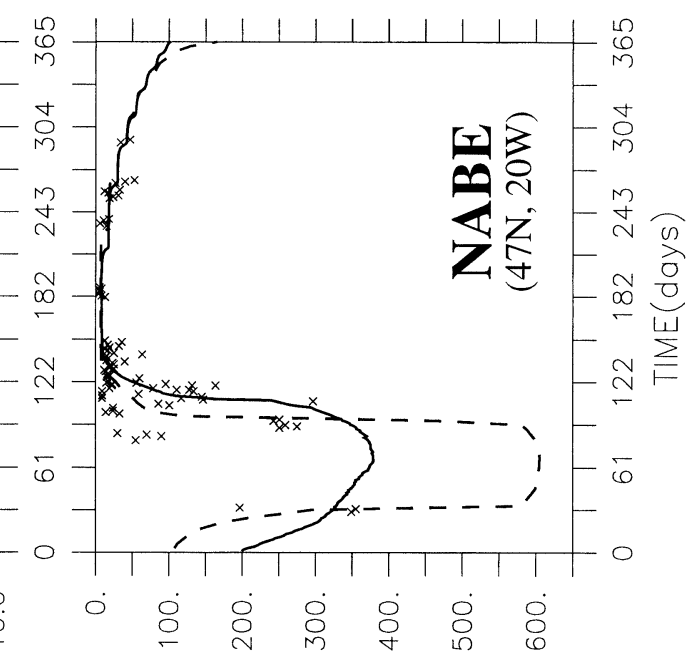

(w) $H \perp d \exists O$

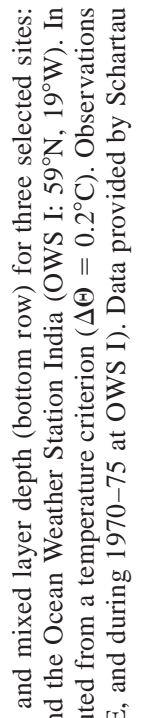

政

定安 웡워 这文市

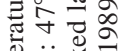

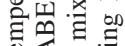
还志 焉泀站 ฐ क凶凶 बे ह : 픔 엉

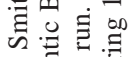
言焉

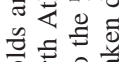

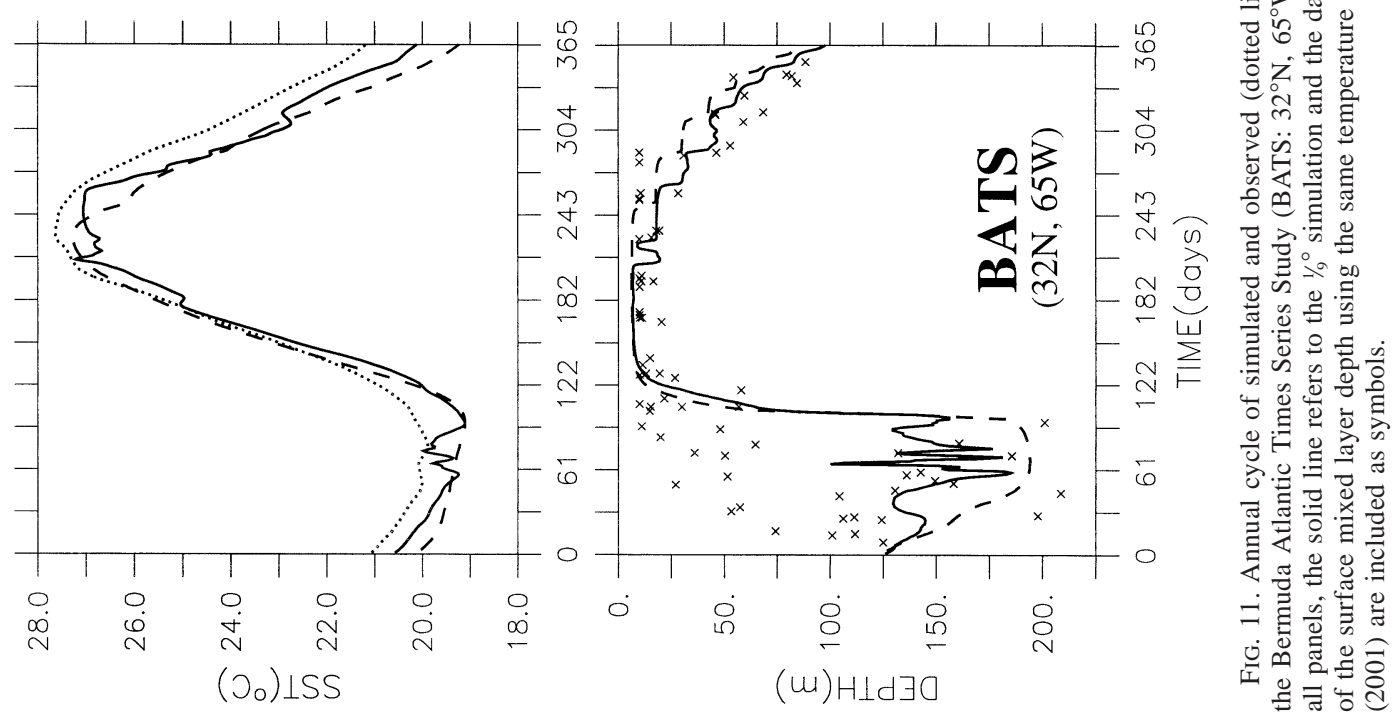


periment (while explaining even greater variability in the observations).

In addition to the winter mixed layers being shallower in the $19^{\circ}$ experiment at all three sites, the transition from deep winter mixed layers to shallow summer mixed layers (and vice versa) tends to occur later (earlier) in the year and is less abrupt. Another feature of the results generated by the $19^{\circ}$ model are signatures of mesoscale variability in both SST and mixed layer depth, which are most pronounced at the BATS and OWSI sites during winter.

The top row of Fig. 11 illustrates that, at all three sites, agreement with the observed 1989-93 average SSTs used in the ECMWF reanalysis (Reynolds and Smith 1994) is considerably improved on switching from $13^{\circ}$ resolution to $19^{\circ}$, which is consistent with the reduction in the surface heat flux correction identified above (Fig. 3). Associated with a reduced surface heat flux correction is an increase of the average heat loss over the mid- and high-latitudinal North Atlantic from $44 \mathrm{~W} \mathrm{~m}^{-2}$ in the $13^{\circ}$ run to $58 \mathrm{~W} \mathrm{~m}^{-2}$ in the $19^{\circ}$ run (averaged from $38^{\circ}-65^{\circ} \mathrm{N}$; see also Fig. 4). Hence, differences between the two models' surface heat fluxes alone cannot explain shallower winter mixed layers in the higher resolution simulation, and changes in the internal dynamics among the two models must be considered.

\section{a. Eddy-induced generation of stratification}

Eddy-induced shoaling of the mixed layer was described by Nurser and Zhang (2000) in the context of an idealized model of a subtropical front in spring. Here, their analysis is extended to the complete annual cycle of a basin-scale model. For a quantitative assessment it is useful to consider the relative potential energy of the water column with respect to the potential energy the column would have were its density uniformly mixed:

$$
\begin{aligned}
E_{\mathrm{pot}, \mathrm{rel}}(z) & =\int_{z}^{0} \rho g z^{\prime} d z^{\prime}-\frac{1}{2} g z \int_{z}^{0} \rho d z^{\prime} \\
& =\int_{z}^{0} \rho g\left(z^{\prime}-\frac{1}{2} z\right) d z^{\prime}
\end{aligned}
$$

where $\rho=\rho\left(x, y, z^{\prime}\right)$. In contrast to the available potential energy of Eq. (2), which basically sums up deviations from the basin-mean density profile, the above definition is local and therefore simplifies the analysis for different water columns with different depths of the surface mixed layer.

For a stably stratified water column between the surface, $z=0$, and a depth level $z$, this results in $E_{\text {pot,rel }}(z)$ $<0$, and energy input would be required to vertically mix the column such that $\partial \rho / \partial z=0$ and $E_{\text {pot,rel }}(z)=0$. Changes in $E_{\text {pot,rel }}(z)$ can arise from surface fluxes of buoyancy or wind-generated turbulent kinetic energy, from advection, and from turbulent mixing in the ocean interior:

$\frac{\partial E_{\mathrm{pot}, \mathrm{rel}}}{\partial t}=\left(\frac{\partial E_{\mathrm{pot}, \mathrm{rel}}}{\partial t}\right)_{\text {surf }}+\left(\frac{\partial E_{\mathrm{pot}, \mathrm{rel}}}{\partial t}\right)_{\mathrm{adv}}+\left(\frac{\partial E_{\mathrm{pot}, \mathrm{rel}}}{\partial t}\right)_{\text {mix }}$.

Among the three terms on the right-hand side, the first one is not considered to be of primary importance here because surface fluxes of turbulent kinetic energy are the same in both models and surface fluxes of buoyancy can vary only in response to changes in the simulated SST [Eq. (1)] and, as discussed above, cannot explain the mixed layer shallowing among the two models. The third term combines effects of horizontal and vertical mixing on $E_{\text {pot,rel }}$. Effects of horizontal mixing are very small compared to advective changes in both model configurations (by orders of magnitude in the zonal average). Vertical mixing, on the other hand, includes convective mixing and can be the dominant term in (4). However, it will respond only indirectly (mainly via changes in density advection) to a change in horizontal grid resolution. In order to better understand the cause of the above identified sensitivity of the simulated mixed layer depth to changes in horizontal grid resolution, the following analysis therefore focusses on advective changes of stratification. Integrating by parts yields

$$
\begin{aligned}
\left(\frac{\partial E_{\mathrm{pot}, \mathrm{rel}}}{\partial t}\right)_{\mathrm{adv}} & =-\int_{z}^{0} \mathbf{u} \cdot \boldsymbol{\nabla} \rho g\left(z^{\prime}-\frac{1}{2} z\right) d z^{\prime} \\
& =g \int_{z}^{0} \frac{\partial}{\partial z}(\mathbf{u} \cdot \boldsymbol{\nabla} \rho) \frac{1}{2}\left(z^{\prime}-z\right) z^{\prime} d z^{\prime}
\end{aligned}
$$

with both $\mathbf{u}$ and $\rho$ being functions of $x, y$, and $z^{\prime}$. Following Nurser and Zhang (2000), this can be decomposed into three terms, namely,

$\left(\frac{\partial E_{\mathrm{pot}, \mathrm{rel}}}{\partial t}\right)_{\mathrm{adv}, \text { strat }}=g \int_{z}^{0} \mathbf{u} \cdot \boldsymbol{\nabla}\left(\frac{\partial \rho}{\partial z}\right) \frac{1}{2}\left(z^{\prime}-z\right) z^{\prime} d z^{\prime}$

representing the effect of advection of stratification,

$$
\left(\frac{\partial E_{\mathrm{pot}, \text { rel }}}{\partial t}\right)_{\text {stretch }}=g \int_{z}^{0} \frac{\partial w}{\partial z} \frac{\partial \rho}{\partial z} \frac{1}{2}\left(z^{\prime}-z\right) z^{\prime} d z^{\prime}
$$

representing the effect of vertical stretching of the stratified water column, and

$$
\left(\frac{\partial E_{\text {pot,rel }}}{\partial t}\right)_{\text {tilt }}=g \int_{z}^{0} \frac{\partial \mathbf{u}_{h}}{\partial z} \cdot \nabla_{h} \rho \frac{1}{2}\left(z^{\prime}-z\right) z^{\prime} d z^{\prime}
$$

representing the tilting of inclined isopycnals by vertical shear of the horizontal flow $\mathbf{u}_{h}$. Vertical stretching increases stratification and reduces $E_{\text {pot,rel }}(z)$ for $(\partial w / \partial z)(\partial \rho /$ $\partial z)>0$, and tilting of density surfaces increases stratification for $(\partial u / \partial z)(\partial \rho / \partial x)>0$ or $(\partial v / \partial z)(\partial \rho / \partial y)>0$.

As pointed out by Nurser and Zhang (2000), both 

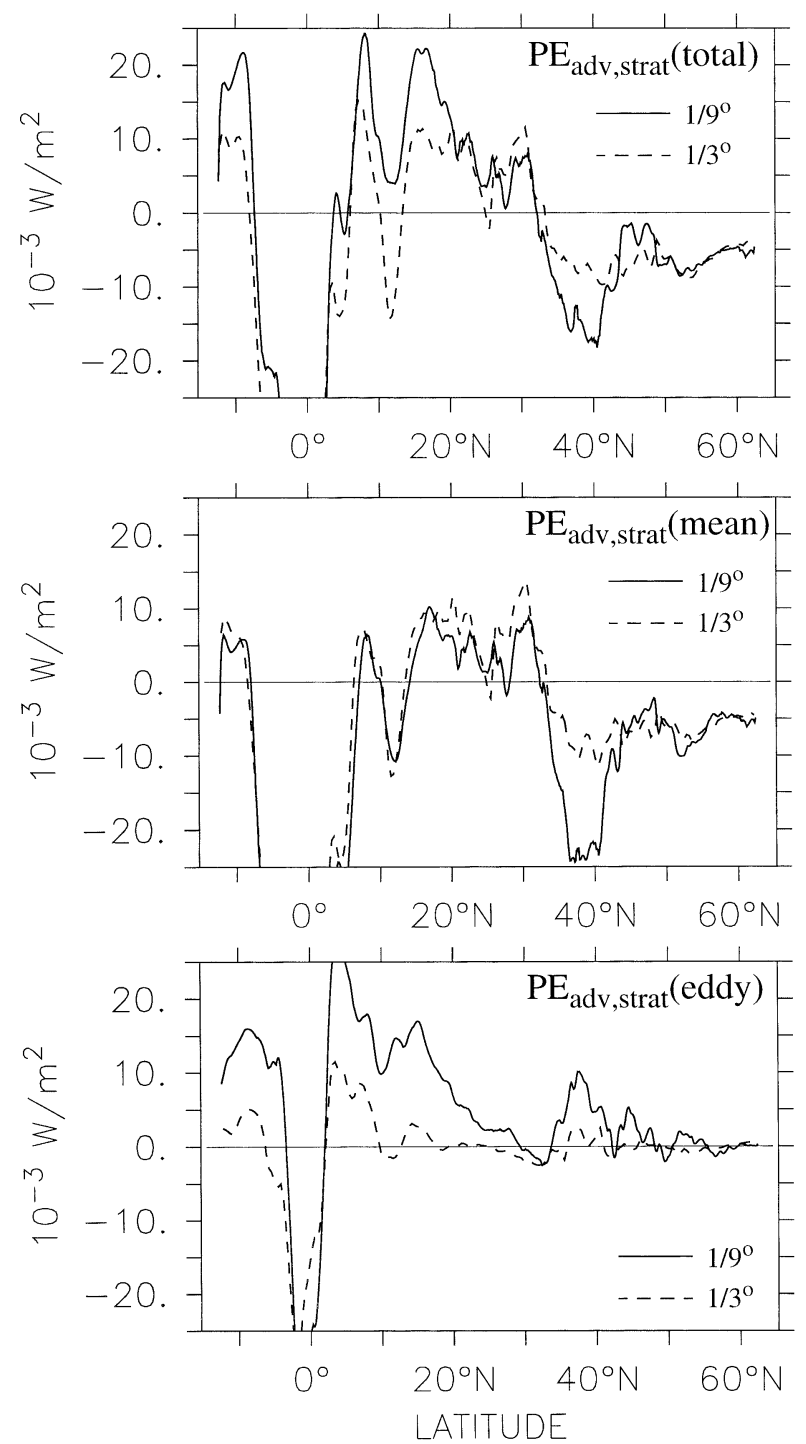

FIG. 12. Annually and zonally averaged change in relative potential energy $E_{\text {potrel }}$ of the upper $1000 \mathrm{~m}$ due to advection of existing stratification [Eq. (6)]. The total energy flux is shown in the top panel, the contribution by the mean flow in the middle one, and the eddy part in the bottom panel. Curves have been smoothed by a $3^{\circ}$ boxcar filter.

stretching and tilting mechanisms require ageostrophic flow. This is obvious for the vertical flow involved in the stretching term, and for the tilting term follows from the orthogonality of vertical shear and lateral density gradient expressed by the thermal wind relation. Relevant examples for ageostrophic flow in the open ocean are the surface Ekman flow and ageostrophic flow associated with meso- and sub-mesoscale processes with large (i.e., not vanishingly small) Rossby numbers. While the ageostrophic Ekman transport depends only on the wind stress applied and hence is identical in both model configurations (though its depth distribution may vary in response to changes in vertical viscosities com-
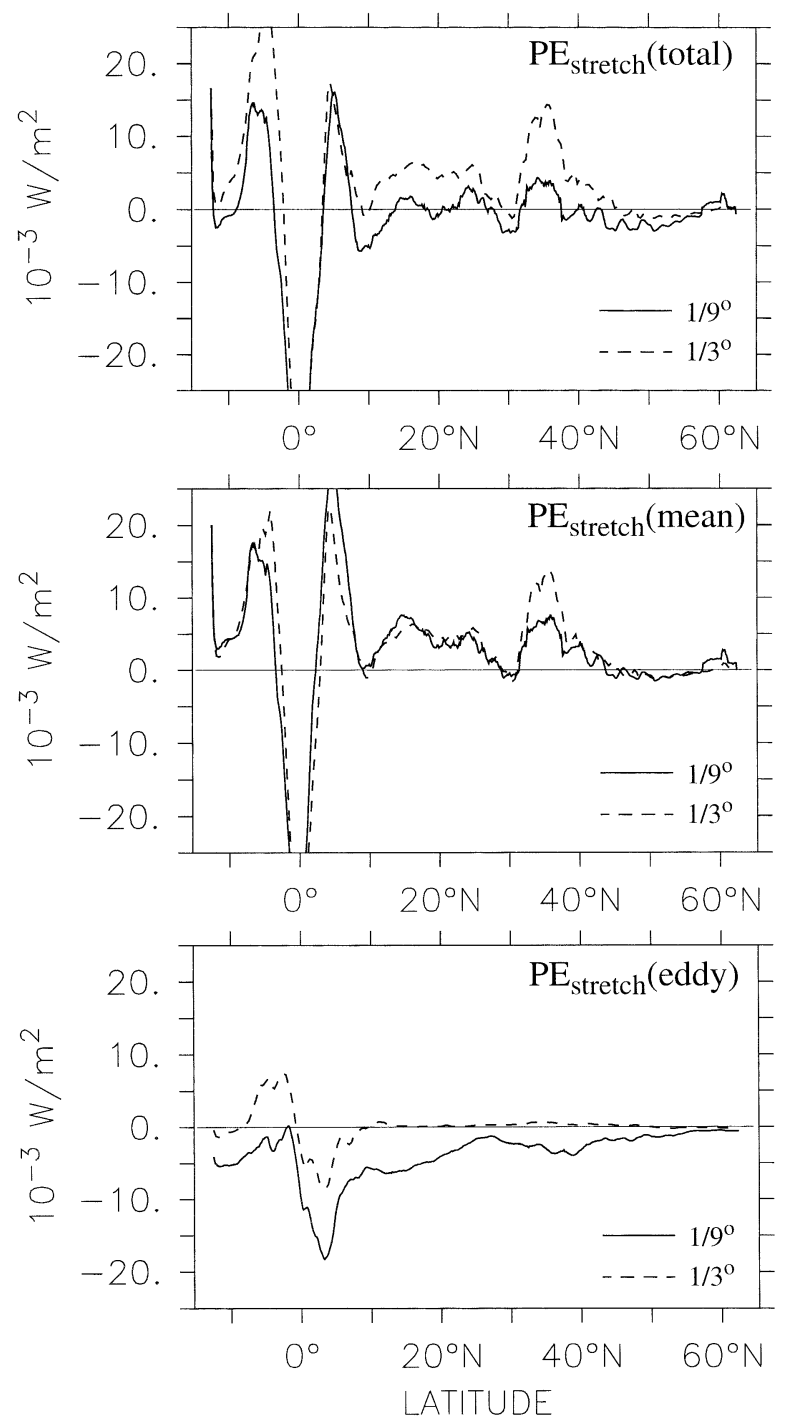

FIG. 13. Annually and zonally averaged change in relative potential energy $E_{\text {potrel }}$ of the upper $1000 \mathrm{~m}$ due to vertical stretching of existing stratification [Eq. (7)]. The total energy flux is shown in the top panel, the contribution by the mean flow in the middle one, and the eddy part in the bottom panel. Curves have been smoothed by a $3^{\circ}$ boxcar filter.

puted by the TKE model), one may presume that higher eddy activity as well as smaller flow scales resolved in the $19^{\circ}$ experiment will increase the strength of the ageostrophic eddy flow component. Note that any differences among the two models' geostrophic flow fields can alter stratification only via the advection of stratification (6).

Zonal and annual averages of the above terms (6)(8) are displayed for $z=1000 \mathrm{~m}$ in Figs. $12-14$ for the two model configurations. The large contributions to the stratification tendency in the Tropics will not be discussed here, as they emerge almost exlusively from the thermocline and do not significantly affect the depth of the mixed layer (see Fig. 10), which is the focus of this 

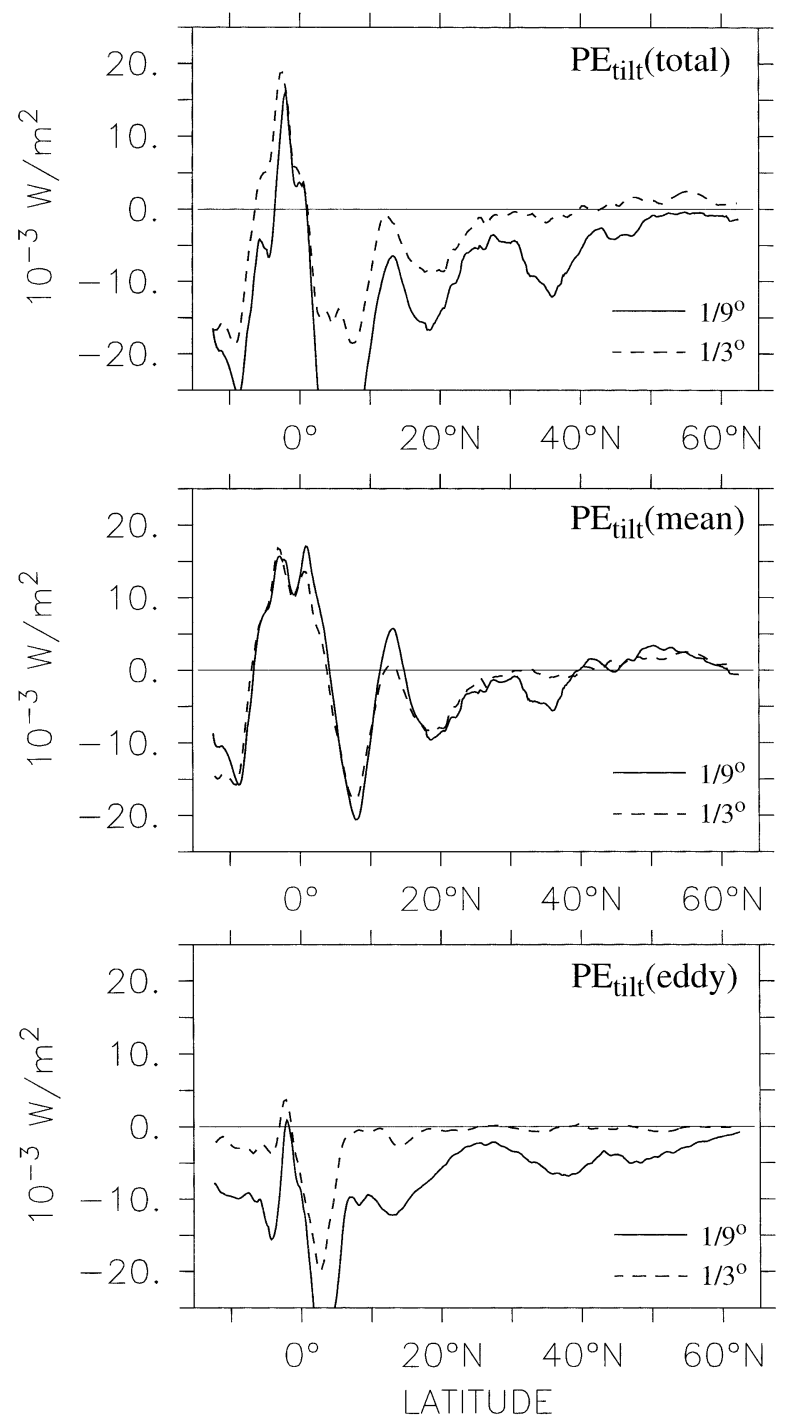

FIG. 14. Annually and zonally averaged change in relative potential energy $E_{\text {potrel }}$ of the upper $1000 \mathrm{~m}$ due to tilting of horizontal density gradients by vertical shear [Eq. (8)]. The total energy flux is shown in the top panel, the contribution by the mean flow in the middle one, and the eddy part in the bottom panel. Curves have been smoothed by a $3^{\circ}$ boxcar filter.

section. In both models, the effect of advection of stratification (6) is to reduce relative potential energy (i.e., to increase stratification) north of about $35^{\circ} \mathrm{N}$ by some 5 to $10\left(\times 10^{-3} \mathrm{~W} \mathrm{~m}^{-2}\right)$ (Fig. 12). This is consistent with the northward advection of heat required to balance the surface heat loss in mid and high latitudes of the North Atlantic. Note that, because most of thermal energy is internal energy and only a minor fraction contributes to gravitational potential energy, a reduction of $E_{\text {pot,rel }}$ by $5 \times 10^{-3} \mathrm{~W} \mathrm{~m}^{-2}$ would, according to the relation

$$
Q_{\mathrm{eq}}=\frac{2 c_{p}}{\alpha g(1000 \mathrm{~m})}\left(\frac{\partial E_{\mathrm{pot}, \mathrm{rel}}}{\partial t}\right)_{\mathrm{tilt}},
$$

have to be balanced by a surface heat loss of $Q_{\text {eq }}=30$ $\mathrm{W} \mathrm{m}{ }^{-2}$ to maintain a vertically mixed layer $1000 \mathrm{~m}$ deep (using a thermal expansion coefficient of $1.5 \times$ $10^{-4} \mathrm{~K}^{-1}$ typical for subpolar near-surface waters). Differences in simulated advection of stratification among the two models are, in the zonal average, largest in the latitude range of the Gulf Stream. Here, advection associated with the mean flow generates more stratification in the $1 / 9^{\circ}$ run than in the $13^{\circ}$ model. Interestingly, the advection of stratification by eddies tends to increase $E_{\text {pot,rel }}$, that is, to reduce stratification at most latitudes. This effect is most pronounced in the $1 \%^{\circ}$ run near the Gulf Stream. An example of how advection of stratification by eddies can result in reduced stratification can be illustrated as follows: whenever an oscillating surface-intensified flow generates intermittent static instabilities, these will be removed by irreversible convective mixing resulting in a net reduction of stratification.

The zonally and annually averaged contribution of vertical stretching [Eq. (7)] is displayed in Fig. 13. This term is positive, that is, destabilizing at most latitudes in the $1 / 3^{\circ}$ run whereas in the $1 / 9^{\circ}$ simulation it is stabilizing at most latitudes north of about $37^{\circ} \mathrm{N}$. With the exception of the Gulf Stream region, changes in the stretching term among the two models are mostly attributed to the eddy component. Zonally averaged contributions of the stretching term change from virtually zero in the $1 / 3$ run to -1 to $-4\left(\times 10^{-3} \mathrm{~W} \mathrm{~m}^{-2}\right)$ in mid and high latitudes in the $19_{9}^{\circ}$ simulation. Recalling that the stretching term requires ageostrophic flow, this seems to agree well with the above presumption that differences in ageostrophic flow among the two models are related mainly to changes in eddy activity.

A similar picture is obtained for the tilting term (8) (Fig. 14): tilting of isopycnals by vertical shear generates more stratification in the higher-resolution run and, apart from the Gulf Stream, the difference is mainly due to the eddy component. Note that the mean ageostrophic flow can at many latitudes lead to a gain of potential energy via the tilting mechanism. One scenario of how this can take place is southward Ekman flow over the subpolar gyre that tends to move dense water over lighter water, thereby decreasing stratification and increasing the potential energy of the water column. On the other hand, the tilting mechanism associated with the time-varying eddy flow field almost exclusively leads to a reduction of potential energy in the $1 /{ }^{\circ}$ run while its contribution is close to zero at all latitudes north of about $10^{\circ} \mathrm{N}$ in the eddy-permitting $1 / 3^{\circ}$ run. A good example for the flow contributing to the tilting term is the ageostrophic flow associated with baroclinic instability that moves lighter water above denser water. Typical rates of potential energy loss by tilting in the $19^{\circ}$ run are about twice as large as for the stretching term $\left[-1\right.$ to $\left.-7\left(\times 10^{-3} \mathrm{~W} \mathrm{~m}^{-2}\right)\right]$.

When integrated over the model domain north of $38^{\circ} \mathrm{N}$, all three terms considered give rise to a net increase in stratification on switching from $1 / 3$ to $1 /{ }^{\circ}$ grid resolution. The total increase amounts to $4.6 \times 10^{-3} \mathrm{~W}$ 
$\mathrm{m}^{-2}$, of which more than $80 \%$ can be attributed to the time varying eddy flow. For the separate processes investigated, the increase is smallest for the advection of stratification that comprises all effects of the geostrophic flow and increases from $-6.7 \times 10^{-3} \mathrm{~W} \mathrm{~m}^{-2}$ in the $1 / 3$ experiment to $-7.2 \times 10^{-3} \mathrm{~W} \mathrm{~m}^{-2}$ in the $1 /{ }^{\circ}$ one. The action of the stretching term changes from destabilizing $\left(+0.5 \times 10^{-3} \mathrm{~W} \mathrm{~m}^{-2}\right)$ to destabilizing $\left(-0.4 \times 10^{-3}\right.$ $\mathrm{W} \mathrm{m}^{-2}$ ) when the horizontal grid is refined. Differences in the generation of stratification among the two models are dominated by the tilting term $\left(-3.2 \times 10^{-3} \mathrm{~W} \mathrm{~m}^{-2}\right)$ that also changes from destabilizing $\left(+1.0 \times 10^{-3} \mathrm{~W}\right.$ $\left.\mathrm{m}^{-2}\right)$ in the eddy-permitting version to stabilizing $(-2.1$ $\times 10^{-3} \mathrm{~W} \mathrm{~m}^{-2}$ ) in the eddy-resolving model.

\section{b. Impact on the buoyancy budget of the mixed layer}

The above analysis has demonstrated that within the upper $1000 \mathrm{~m}$ there is a substantial increase in the generation of stratification when switching from the eddypermitting model to the eddy-resolving one. Since both models exhibit an approximately stable seasonal cycle, any differences in the advective generation of stratification must, on average, be balanced by differences in turbulent mixing or surface buoyancy fluxes. In order to evaluate the extent to which surface buoyancy fluxes may balance differences in the advective generation of stratification, only the surface mixed layer in direct contact with the atmosphere will be considered in the following.

When restricting the above analysis to the surface mixed layer, advective impacts on stratification can essentially be reduced to the tilting term. This is because in the absence of vertical density gradients (the very small gradients that are present in reality and in the TKE closure employed here are not relevant in this analysis) advection of stratification and vertical stretching both can be neglected. Contributions that arise from advection of stratification across the sloping base of the mixed layer turn out to be small compared to the tilting term in both model configurations investigated here. The tilting term, in contrast, is a function of horizontal density gradients that overall have the same order of magnitude within and below the mixed layer. Note, however, that action of the tilting term requires vertical shear of the horizontal velocity components within the mixed layer.

The annually averaged tendency of the tilting term to generate stratification within the seasonally varying surface mixed layer is displayed in Fig. 15. The 1/\% simulation shows negative values and hence a stabilizing effect of the tilting term over most parts of the midand high-latitudinal North Atlantic. In the eddy-permitting $13^{\circ}$ simulation, in contrast, the area over which the tilting term acts to stabilize the mixed layer is much reduced, and north of $50^{\circ} \mathrm{N}$ positive values dominate in the zonal mean. These positive values arise from southward advection of dense surface water by the surface Ekman flow. With the Ekman transport being the same in both simulations, either changes in the mean lateral density gradient or ageostrophic flow other than Ekman flow must be responsible for differences in the tilting term among the models. Although the temporally varying depth of the mixed layer precludes a simple separation of the contribution by tilting into mean and eddy parts, results of the previous subsection suggest that eddy contributions dominate.

Assuming for simplicity that the surface heat flux were the only mechanism active in balancing the stabilizing effect of the tilting term (wind stirring may be important particularly in relatively shallow mixed layers), one can compute the equivalent surface heat flux, $Q_{\text {eq }}$ required to locally balance the potential energy loss caused by the tilting term:

$$
Q_{\mathrm{eq}}=\frac{2 c_{p}}{\alpha g h_{\text {mix }}}\left(\frac{\partial E_{\mathrm{pot}, \text { rel }}}{\partial t}\right)_{\text {tilt }},
$$

where $c_{p}$ is the heat capacity, $\alpha$ the thermal expansion coefficient, and $h_{\text {mix }}$ the depth of the surface mixed layer. As shown by Fig. 16, surface heat fluxes required to sustain the seasonal cycle of the mixed layer against the action of the tilting term are negative (i.e., cooling) over most of the model region in the $1 / 9^{\circ}$ simulation. North of about $35^{\circ} \mathrm{N}$, typical values reach from a few watts per square meter in the eastern part of the subpolar gyre to about $-30^{\circ} \mathrm{W} \mathrm{m}^{-2}$ in the Gulf Stream region. For the eddy-permitting $13^{\circ}$ simulation, $Q_{\mathrm{eq}}$ is instead positive over large regions of the subpolar gyre (not shown), reflecting the destabilizing action of the tilting term (see Fig. 15) presumably by the surface Ekman flow.

Differences in the equivalent surface heat flux $Q_{\mathrm{eq}}$ between the two models can be compared to differences in the actual surface heat flux simulated by the models. In the zonal average, mid- and high-latitude values of $Q_{\text {eq }}$ are smaller by 3 to $10 \mathrm{~W} \mathrm{~m}^{-2}$ in the $19^{\circ}$ simulation (Fig. 17). Averaged over the region north of $35^{\circ} \mathrm{N}$, values of $Q_{\mathrm{eq}}$ are smaller by $5.3 \mathrm{~W} \mathrm{~m}^{-2}$ in the $1 /{ }^{\circ}$ simulation and can account for about one third of the actual difference in simulated surface heat fluxes over the same region $\left(15.1 \mathrm{~W} \mathrm{~m}^{-2}\right.$; see section $\left.3 b\right)$. In addition to turbulent mixing across the base of the mixed layer, the remaining difference in simulated surface heat fluxes can be explained by differences in processes that do not generate stratification within the mixed layer, for example, vertically uniform advection of temperature.

\section{Discussion and conclusions}

Two configurations of a primitive-equation North Atlantic model, differing only in their horizontal grid resolution of $13^{\circ}$ and $19^{\circ}$ respectively, have been analyzed and compared with observations focussing on the representation of upper ocean dynamics and winter mixed layer depths. This was initially motivated by preliminary results of a pelagic ecosystem model coupled into both eddy-permitting and eddy-resolving circulation 


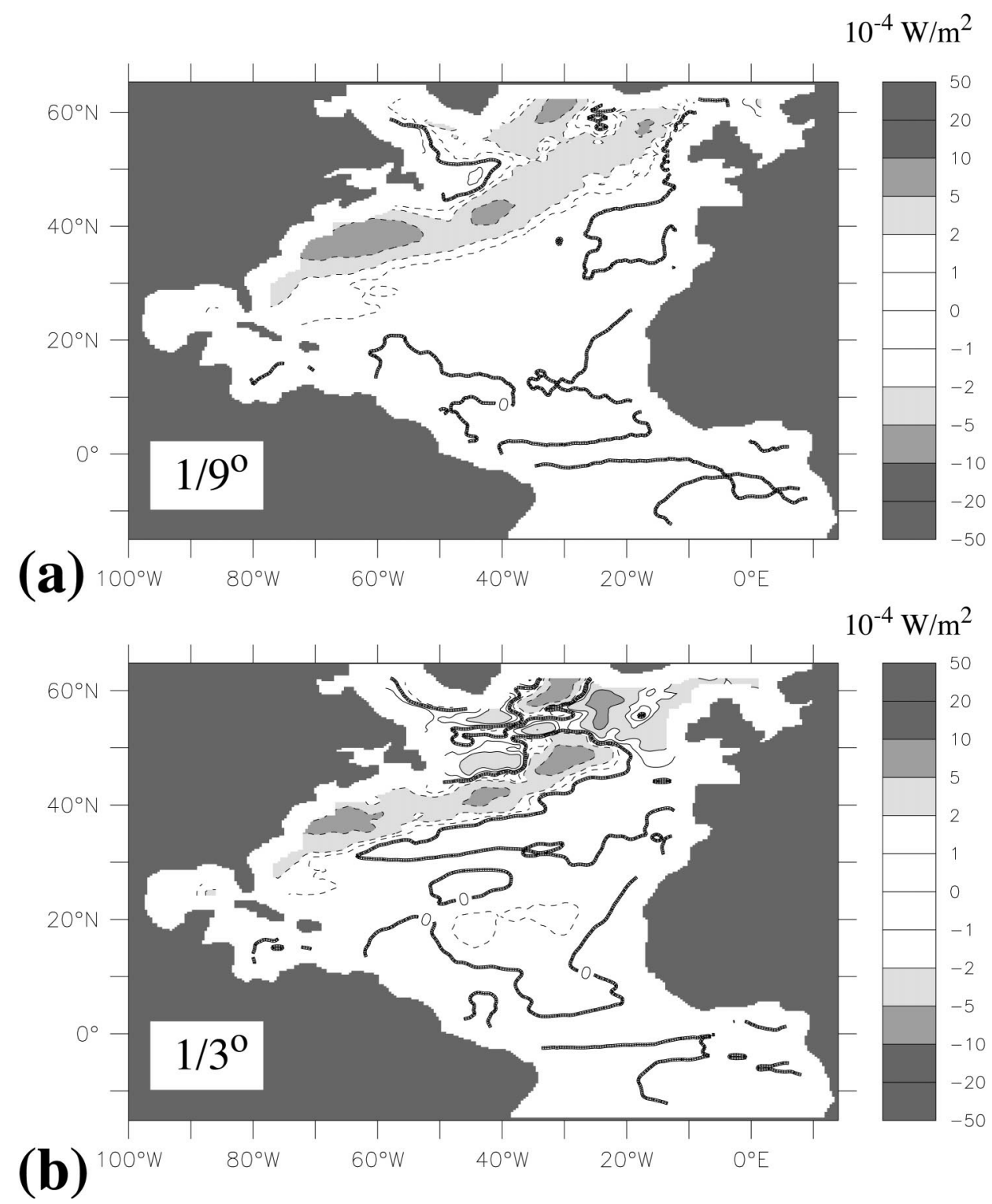

FIG. 15. Annually averaged change in relative potential energy $E_{\text {pot,rel }}$ of the seasonally varying surface mixed layer, defined by a density criterion of $\Delta \sigma=0.01 \mathrm{~kg} \mathrm{~m}^{-3}$, due to tilting of horizontal density gradients by vertical shear [Eq. (8)]: (a) $1 / 9^{\circ}$ simulation, (b) $1 / 3^{\circ}$ simulation.

models. Particularly, improvement in the simulated cycling of nutrients was found to be related to a more realistic representation of winter mixed layer depths in the higher resolution experiment. A better understanding of the underlying physical processes was the principal aim of the present study.

Similar to the results reported by Smith et al. (2000), a number of improvements have been identified in the simulated flow field on refining the horizontal grid resolution from eddy-permitting to eddy-resolving, ranging from a somewhat better Gulf Stream separation to more realistic surface heat fluxes and larger northward heat transport by the mean flow. As could be expected from previous studies, which showed that horizontal resolu- tion of the $13^{\circ}$ model was not sufficient to adequately represent the observed eddy field north of about $30^{\circ} \mathrm{N}$ (Stammer and Böning 1992), the increase in eddy activity on switching from $13^{\circ}$ to $19^{\circ}$ resolution is largest in mid and high latitudes (Fig. 8). Moreover, the $19^{\circ}$ model reproduces observed spectra of SSH variability in general much better than the $13^{\circ}$ version (Fig. 7), suggesting that eddy length scales and dynamics are well resolved in the high resolution version.

Winter mixed layers were found to be systematically shallower in mid and high latitudes in the $19^{\circ}$ run, by typically $50-500 \mathrm{~m}$ compared to the $13^{\circ}$ simulation, thereby agreeing much better with available observations. The reduction of mixing depths could be related 


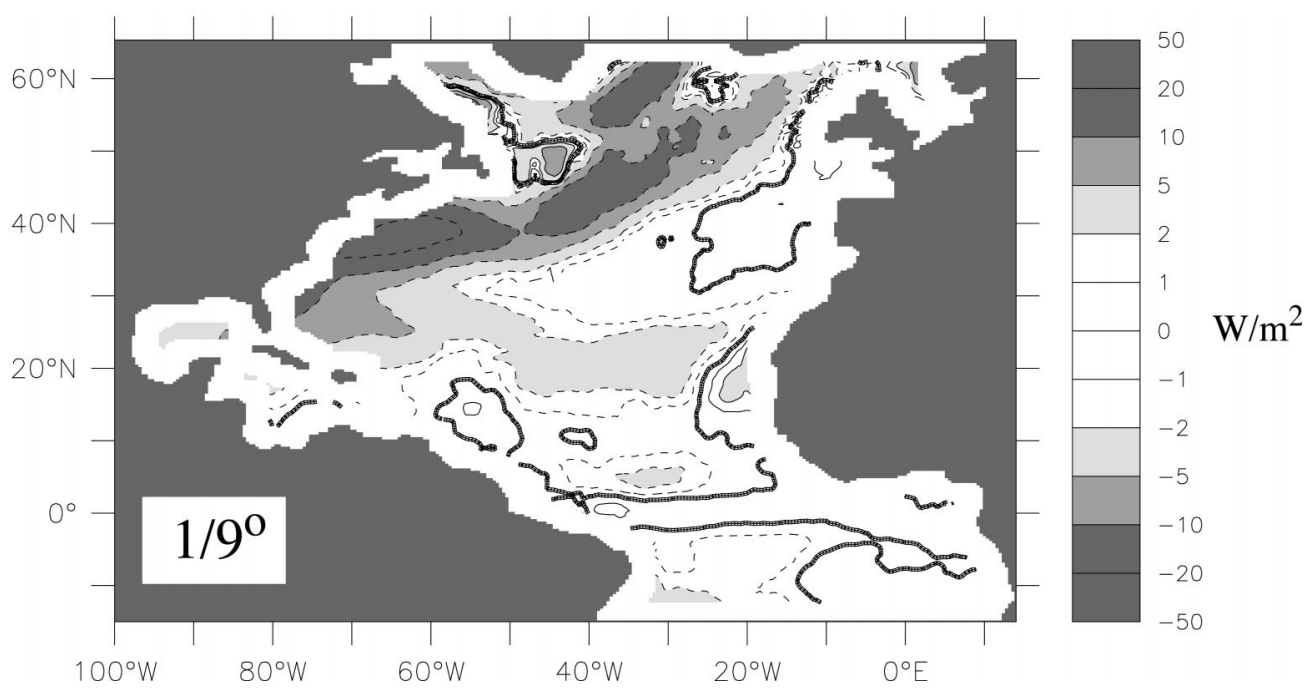

FIG. 16. Annual equivalent surface heat flux [Eq. (10)] required to balance the generation of stratification in the surface mixed layer of the $1 \%{ }^{\circ}$ simulation.

to an overall decrease in available potential energy and an associated increase in stratification. An analysis of the potential energy budget quantified the generation of stratification by advection of stratification, by vertical

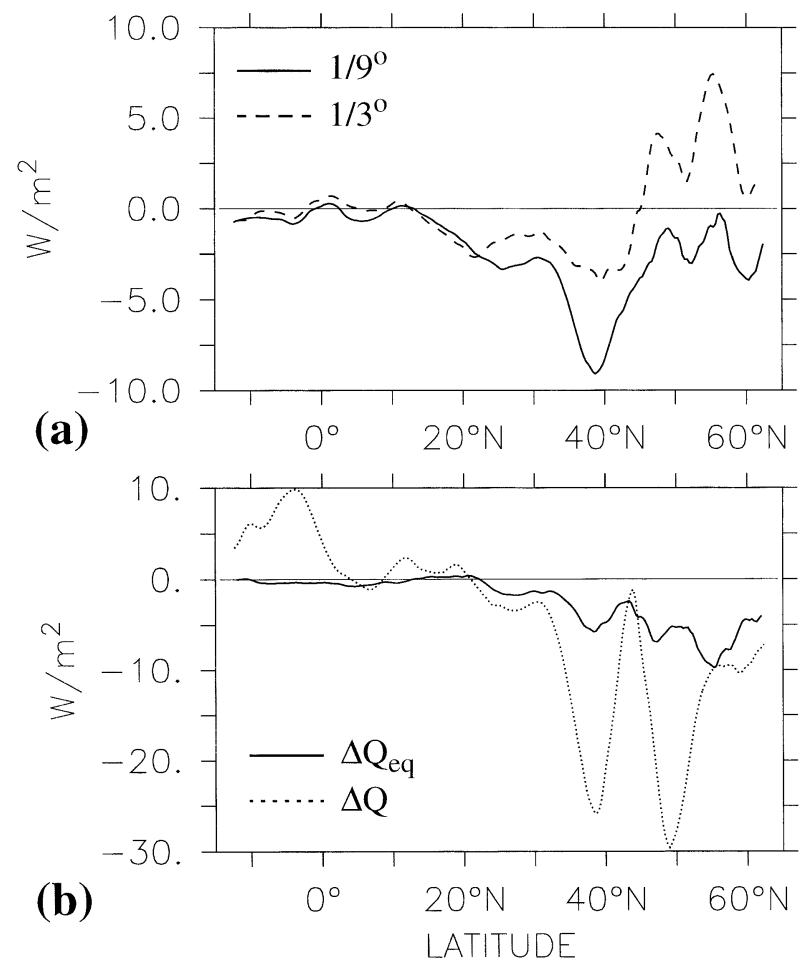

FIG. 17. (a) Zonally and annually averaged simulated equivalent surface heat flux [Eq. (10)] required to balance the generation of stratification in the surface mixed layer. (b) The solid line refers to the difference in the equivalent surface heat fluxes $\left(19^{\circ}\right.$ minus $1 / 3^{\circ}$ model). The dotted line is the difference of the actual surface heat fluxes simulated by the two models $\left(1 /{ }^{\circ}\right.$ minus $\left.1 / 3^{\circ}\right)$. Curves have been smoothed by a $3^{\circ}$ boxcar filter. stretching, and by tilting of lateral density gradients by vertically sheared flow. Of these processes, only advection of stratification may reflect geostrophic circulation. Both stretching and tilting mechanisms require ageostrophic flow. While the two models showed relatively little difference in the generation of stratification by advection of stratification, a substantial increase in the generation of stratification on switching from $13^{\circ}$ to $19^{\circ}$ resolution could be attributed to the stretching and tilting mechanisms related to the time-varying flow. For the region north of $38^{\circ} \mathrm{N}$, total advective generation of stratification within the upper $1000 \mathrm{~m}$ was higher by about $4.6 \times 10^{-3} \mathrm{~W} \mathrm{~m}^{-2}$ in the $19^{\circ}$ simulation, which would roughly correspond to an extra surface heat flux of $30 \mathrm{~W} \mathrm{~m}^{-2}$ if the upper $1000 \mathrm{~m}$ were homogeneously mixed. Approximately two thirds of this difference between the two models could be attributed to eddy-induced tilting of lateral density gradients by vertical shear.

A reduction of available potential energy as a net effect of eddies generated by baroclinic instability is also underlying recent eddy-parameterizations used in coarse-resolution ocean models (Gent et al. 1995). Differences in simulated stratification, mixed layer depths, and surface heat budget found among the two model configurations used in the present study reaffirm the conclusion of Roberts and Marshall (1998) that such parameterizations may also be required in high-resolution models, although it remains open to what extent this statement would apply to the eddy-resolving simulation as well. While the results of this study and also those reported by Smith et al. (2000) suggest that approximately resolving the first baroclinic Rossby radius is sufficient for a realistic representation of eddy scales and intensities, it will have to be tested by future simulations at even higher resolution whether convergence 
of eddy-induced impacts on the large-scale cycling of energy, heat and mass has yet been reached.

In accordance with recent studies using idealized process models (Haine and Marshall 1998; Legg et al. 1998; Nurser and Zhang 2000), eddy-induced generation of stratification in the eddy-resolving North Atlantic model is not restricted to the stably stratified thermocline. Even within the simulated surface mixed layer there is significant generation of stratification by vertical shear acting on horizontal density gradients. A comparison with the surface heat fluxes indicates that about one third $\left(\sim 5 \mathrm{~W} \mathrm{~m}^{-2}\right)$ of the enhanced cooling simulated by the higher resolution model over mid and high latitudes may be required to balance generation of stratification by tilting of isopycnals within the mixed layer. Because the tilting process is inherently three-dimensional, it cannot straightforwardly be included in typically one-dimensional routines of convective mixing in the surface mixed layer. Present eddy parameterizations for coarseresolution ocean circulation models, on the other hand, have been built with particular emphasis on the stably stratified thermocline and therefore may not always work well in the surface mixed layer. Because here the definition of isopycnal slopes or layer thickness becomes problematic, mixing coefficients are usually tapered to zero in the mixed layer. In order to consider the generation of stratification in the mixed layer in noneddy-resolving models, standard applications of existing eddy parameterizations would have to be modified by considering lateral density gradients within the mixed layer. The present study suggests that the process of eddy-induced generation of stratification within the surface mixed layer may be important for an accurate simulation of mixed layer depths and water mass properties set by air-sea exchange in mid and high latitudes.

Acknowledgments. The altimeter data used in Figs. 6 and 7 were produced by the CLS Space Oceanography Division as part of the Environment and Climate EU AGORA (ENV4-CT9560113) and DUACS (ENV44T96-0357). The help of Markus Schartau and Heiner Dietze in analyzing hydrographic and altimetric data, and constructive comments by Carsten Eden and two anonymous reviewers, are acknowledged.

\section{REFERENCES}

Barnier, B., L. Hua, and C. Le Provost, 1991: On the catalytic role of high baroclinic modes in eddy-driven large scale circulation. J. Phys. Oceanogr., 21, 976-997.

_ _ L. Siefridt, and P. Marchesiello, 1995: Surface thermal boundary condition for a global ocean circulation model from a threeyear climatology of ECMWF analyses. J. Mar. Syst., 6, 363380 .

Beckmann, A., C. W. Böning, C. Köberle, and J. Willebrand, 1994: Effects of increased horizontal resolution in a simulation of the North Atlantic Ocean. J. Phys. Oceanogr., 24, 326-344.

Blanke, B., and P. Delecluse, 1993: Variability of the tropical Atlantic Ocean simulated by a general circulation model with two different mixed-layer physics. J. Phys. Oceanogr., 23, 1363-1388.
Böning, C. W., and R. Budich, 1992: Eddy dynamics in a primitive equation model: Sensitivity to horizontal resolution and friction. J. Phys. Oceanogr., 22, 361-381.

_ - W. R. Holland, F. O. Bryan, G. Danabasoglu, and J. C. McWilliams, 1995: An overlooked problem in model simulations of the thermohaline circulation and heat transport in the Atlantic Ocean. J. Climate, 8, 515-523.

Bryan, F. O., and W. R. Holland, 1989: A high resolution simulation of the wind- and thermohaline-driven circulation in the North Atlantic Ocean. Parameterization of Small-Scale Processes, P. Müller and D. Henderson, Eds., Hawaii Institute of Geophysics, Manoa, 99-115.

Bryan, K., 1986: Poleward buoyancy transport in the ocean and mesoscale eddies. J. Phys. Oceanogr., 16, 927-933.

Chao, Y., A. Gangopadhyay, F. O. Bryan, and W. R. Holland, 1996: Modeling the Gulf Stream: How far from reality? Geophys. Res. Lett., 23, 3155-3158.

da Silva, A. M., C. C. Young, and S. Levitus, 1994: Algorithms and Procedures. Vol. 1, Atlas of Surface Marine Data 1994, NOAA Atlas NESDIS 6, $83 \mathrm{pp}$.

Döscher, R., C. W. Böning, and P. Herrmann, 1994: Response of circulation and heat transport in the North Atlantic to changes in thermohaline forcing in northern latitudes: A model study. $J$. Phys. Oceanogr., 24, 2306-2320.

Drijfhout, S. S., 1994: Sensitivity of eddy-induced heat transport to diabatic forcing. J. Geophys. Res., 99, 18 481-18 499.

Ferry, N., G. Reverdin, and A. Oschlies, 2000: Seasonal sea level variability in the North Atlantic. J. Geophys. Res., 105, 63076326.

Gaspar, P., Y. Gregoris, and J.-M. Lefevre, 1990: A simple eddy kinetic energy model for simulations of the oceanic vertical mixing: Tests at station Papa and Long-Term Upper Ocean Study site. J. Geophys. Res., 95, 16 179-16 193.

Gent, P. R., J. Willebrand, T. J. McDougall, and J. C. McWilliams, 1995: Parameterizing eddy-induced tracer transports in ocean circulation models. J. Phys. Oceanogr., 25, 463-474.

Gibson, J. K., P. Kallberg, S. Uppala, A. Hernandez, A. Nomura, and E. Serrano, 1997: ERA description. ECMWF Re-analysis Project Report Series 1, 72 pp.

Haine, T. W. N., and J. Marshall, 1998: Gravitational, symmetric, and baroclinic instability of the ocean mixed layer. J. Phys. Oceanogr., 28, 634-658.

Haney, R. L., 1971: Surface thermal boundary condition for ocean circulation models. J. Phys. Oceanogr., 1, 241-248.

Jakob, C., 1999: Cloud cover in the ECMWF reanalysis. J. Climate, 12, 947-959.

Jia, Y., 2000: The formation of the Azores Current due to Mediterranean overflow in a modeling study of the North Atlantic. $J$. Phys. Oceanogr., 30, 2342-2358.

Johns, W. E., T. J. Shay, J. M. Bane, and D. R. Watts, 1995: Gulf Stream structure, transport, and recirculation near $68^{\circ} \mathrm{W}$. J. Geophys. Res., 100, 817-838.

Koeve, W., 2001: Wintertime nutrients in the North Atlantic-New approaches and implications for new production estimates. Mar. Chem., 74, 245-260.

Ledwell, J. R., A. J. Watson, and C. S. Law, 1993: Evidence for slow mixing across the pycnocline from an open-ocean tracer-release experiment. Nature, 364, 701-703.

Legg, S., J. McWilliams, and J. Gao, 1998: Localization of deep ocean convection by a mesoscale eddy. J. Phys. Oceanogr., 28, 944-970.

Le Traon, P. Y., and F. Ogor, 1998: ERS-1/2 orbit error improvement using TOPEX/Poseidon: The $2 \mathrm{~cm}$ challenge. J. Geophys. Res., 103, 8045-8057.

_, F. Nadal, and N. Ducet, 1998: Am improved mapping method of multi-satellite altimeter data. J. Atmos. Oceanic Technol., 15, $522-534$.

Levitus, S., 1982: Climatological Atlas of the World Ocean. NOAA Prof. Paper 13, 173 pp. and 17 microfiche. 
_ Atlas 1994, NOAA Atlas NESDIS 3, 99 pp.

Macdonald, A. M., 1998: The global ocean circulation: A hydrographic estimate and regional analysis. Progress in Oceanography, Vol. 41, Pergamon, 281-382.

McGillicuddy, D. J., Jr., and A. R. Robinson, 1997: Eddy-induced nutrient supply and new production in the Sargasso Sea. DeepSea Res. I, 44, 1427-1450.

Michaels, A. F., and A. H. Knap, 1996: Overview of the U.S. JGOFS Bermuda Atlantic Time-series Study and the Hydrostation S program. Deep-Sea Res. II, 43, 157-198.

Nurser, A. J. G., and J. W. Zhang, 2000: Eddy-induced mixed layer shallowing and mixed layer/thermocline exchange. J. Geophys. Res., 105, $21851-21868$.

Oschlies, A., and V. Garçon, 1998: Eddy induced enhancement of primary production in a model of the North Atlantic Ocean. Nature, 394, 266-269.

—, and - 1999: An eddy-permitting coupled physical-biological model of the North Atlantic. 1. Sensitivity to advection numerics and mixed layer physics. Global Biogeochem. Cycles, 13, 135-160.

- W. Koeve, and V. Garçon, 2000: An eddy-permitting coupled physical-biological model of the North Atlantic. Part II: Ecosystem dynamics and comparison with satellite and JGOFS local studies data. Global Biogeochem. Cycles, 14, 499-523.

Özgökmen, T. M., E. P. Chassignet, and C. G. H. Rooth, 2001: On the connection between Mediterranean outflow and the Azores Current. J. Phys. Oceanogr., 31, 461-480.

Pacanowski, R., K. Dixon, and A. Rosati, 1991: The GFDL modular ocean model users guide, version 1. GFDL Ocean Group Tech. Rep. 2, 376 pp.

Paiva, A. M., J. T. Hargrove, E. P. Chassignet, and R. Bleck, 1999:
Turbulent behavior of a fine mesh (1/12 degrees) numerical simulation of the North Atlantic. J. Mar. Syst., 21, 307-320.

Paulson, C. A., and J. J. Simpson, 1977: Irradiance measurements in the upper ocean. J. Phys. Oceanogr., 7, 952-956.

Pedlosky, J., 1979: Geophysical Fluid Dynamics. Springer-Verlag, $624 \mathrm{pp}$.

Reid, R. O., B. A. Elliot, and D. B. Olson, 1981: Available potential energy: A clarification. J. Phys. Oceanogr., 11, 15-29.

Reynolds, R. W., and T. M. Smith, 1994: Improved global sea surface temperature analysis using optimum interpolation. J. Climate, $\mathbf{7}$, 929-948.

Roberts, M., and D. Marshall, 1998: Do we require adiabatic dissipation schemes in eddy-resolving ocean models? J. Phys. Oceanogr., 28, 2050-2063.

Schartau, M., 2001: Data assimilation studies of marine, nitrogen based, ecosystem models in the North Atlantic Ocean. Ph.D. thesis, University of Kiel, $128 \mathrm{pp}$.

Smith, R. D., M. E. Maltrud, F. O. Bryan, and M. W. Hecht, 2000: Numerical simulation of the North Atlantic Ocean at $1 / 10^{\circ}$. J. Phys. Oceanogr., 30, 1532-1561.

Stammer, D., and C. W. Böning, 1992: Mesoscale varibility in the Atlantic Ocean from GEOSAT Altimetry and WOCE high resolution numerical modeling. J. Phys. Oceanogr., 22, 732-752.

Treguier, A. M., 1992: Kinetic energy analysis of an eddy resolving, primitive equation model of the North Atlantic. J. Geophys. Res., 97, 687-701.

Trenberth, K. E., J. M. Carton, and D. P. Stepaniak, 2001: The atmospheric energy budget and implications for surface fluxes and ocean heat transports. Climate Dyn., 17, 259-276.

Willebrand, J., B. Barnier, C. Böning, C. Dieterich, P. D. Killworth, C. LeProvost, Y. Jia, J.-M. Molines, and A. L. New, 2001: Circulation characteristics in three eddy-permitting models of the North Atlantic. Progress in Oceanography, Vol. 48, Pergamon, 123-161. 